\title{
United Nations Basic Space Science Initiative (UNBSSI) 1991-2012 and Beyond
}

\author{
A. M. Mathai1, ${ }^{1}$, H. J. Haubold ${ }^{1,3}$ \\ ${ }^{1}$ Centre for Mathematical and Statistical Sciences, Peechi Campus, KFRI, Peechi, Kerala, India \\ ${ }^{2}$ Department of Mathematics and Statistics, McGill University, Montreal, Canada \\ ${ }^{3}$ Office for Outer Space Affairs, United Nations, Vienna International Centre, Vienna, Austria \\ Email: mathai@math.mcgill.ca, hans.haubold@gmail.com, werner.balogh@unoosa.org
}

How to cite this paper: Mathai, A. M., \& Haubold, H. J. (2018). United Nations Basic Space Science Initiative (UNBSSI) 1991-2012 and Beyond. Creative Education, 9, 192-248.

https://doi.org/10.4236/ce.2018.92015

Received: July 1, 2017

Accepted: February 10, 2018

Published: February 13, 2018

Copyright $\odot 2018$ by authors and Scientific Research Publishing Inc. This work is licensed under the Creative Commons Attribution International License (CC BY 4.0).

http://creativecommons.org/licenses/by/4.0/ (c) (i) Open Access

\begin{abstract}
The present paper contains an overview and summary on the achievements of the basic space science initiative in terms of donated and provided planetariums, astronomical instruments, and space weather instruments, particularly operating in developing nations. These instruments have been made available to respective host countries, particularly developing nations, through the series of twenty basic space science workshops, organized through the United Nations Programme on Space Applications since 1991. Organized by the United Nations, the European Space Agency (ESA), the National Aeronautics and Space Administration (NASA) of the United States of America, and the Japan Aerospace Exploration Agency (JAXA), the basic space science workshops were organized as a series of workshops that focused on basic space science (1991-2004), the International Heliophysical Year 2007 (2005-2009), and the International Space Weather Initiative (2010-2012) proposed by the Committee on the Peaceful Uses of Outer Space on the basis of discussions of its Scientific and Technical Subcommittee, as reflected in the reports of the Subcommittee. Workshops on the International Space Weather Initiative in the series were hosted by the Government of Egypt in 2010 (see A/AC.105/994), the Government of Nigeria in 2011, and the Government of Ecuador in 2012 (see A/AC.105/1030). Workshops on the International Heliophysical Year 2007 were hosted by the United Arab Emirates in 2005 (see A/AC.105/856), India in 2006 (see A/AC.105/882), Japan in 2007 (see A/AC.105/902), Bulgaria in 2008 (see A/AC.105/919) and the Republic of Korea in 2009 (see A/AC.105/964). Workshops on basic space science were hosted by the Governments of India (see A/AC.105/489), Costa Rica and Colombia (see A/AC.105/530), Nigeria (see A/AC.105/560/Add.1), Egypt (see A/AC.105/580),
\end{abstract}


Sri Lanka (see A/AC.105/640), Germany (see A/AC.105/657), Honduras (see A/AC.105/682), Jordan (see A/AC.105/723), France (see A/AC.105/742), Mauritius (see A/AC.105/766), Argentina (see A/AC.105/784) and China (see A/AC.105/829). All workshops were co-organized by the International Astronomical Union (IAU) and the Committee on Space Research (COSPAR).

\section{Keywords}

Astronomy, Physics, Education, Telescopes, Planetariums, Instruments

\section{Introduction}

The basic space science initiative was a long-term effort for the development of astronomy and space science through regional and international cooperation in this field on a worldwide basis, particularly in developing nations. Basic space science workshops were co-sponsored and co-organized by ESA, JAXA, and NASA.

A series of workshops on basic space science was held from 1991 to 2004 (India 1991, Costa Rica and Colombia 1992, Nigeria 1993, Egypt 1994, Sri Lanka 1995, Germany 1996, Honduras 1997, Jordan 1999, France 2000, Mauritius 2001, Argentina 2002, and China 2004; http://neutrino.aquaphoenix.com/un-esa/) and addressed the status of astronomy in Asia and the Pacific, Latin America and the Caribbean, Africa, and Western Asia. Through the lead of Professor Dr. Masatoshi Kitamura (1926-2012) from the National Astronomical Observatory Japan, astronomical telescope facilities were inaugurated in seven developing nations and planetariums were established in twenty developing nations based on the donation of respective equipment by Japan.

Pursuant to resolutions of the Committee on the Peaceful Uses of Outer Space of the United Nations (COPUOS) and its Scientific and Technical Subcommittee, since 2005, these workshops focused on the preparations for and the follow-ups to the International Heliophysical Year 2007 (UAE 2005, India 2006, Japan 2007, Bulgaria 2008, South Korea 2009;

http://www.unoosa.org/oosa/SAP/bss/ihy2007/index.html). IHY's legacy is the current operation of 16 worldwide instrument arrays with close to 1000 instruments recording data on solar-terrestrial interaction from coronal mass ejections to variations of the total electron content in the ionosphere (http://iswi-secretariat.org/). Instruments are provided to hosting institutions by entities of Armenia, Brazil, France, Israel, Japan, Switzerland, and the United States.

Starting in 2010, the workshops focused on the International Space Weather Initiative (ISWI) as mandated in a three-year-work plan as part of the deliberations of COPUOS. Workshops on ISWI were scheduled for Egypt in 2010 for Western Asia, Nigeria in 2011 for Africa, and Ecuador in 2012 for Latin America and the Caribbean. 


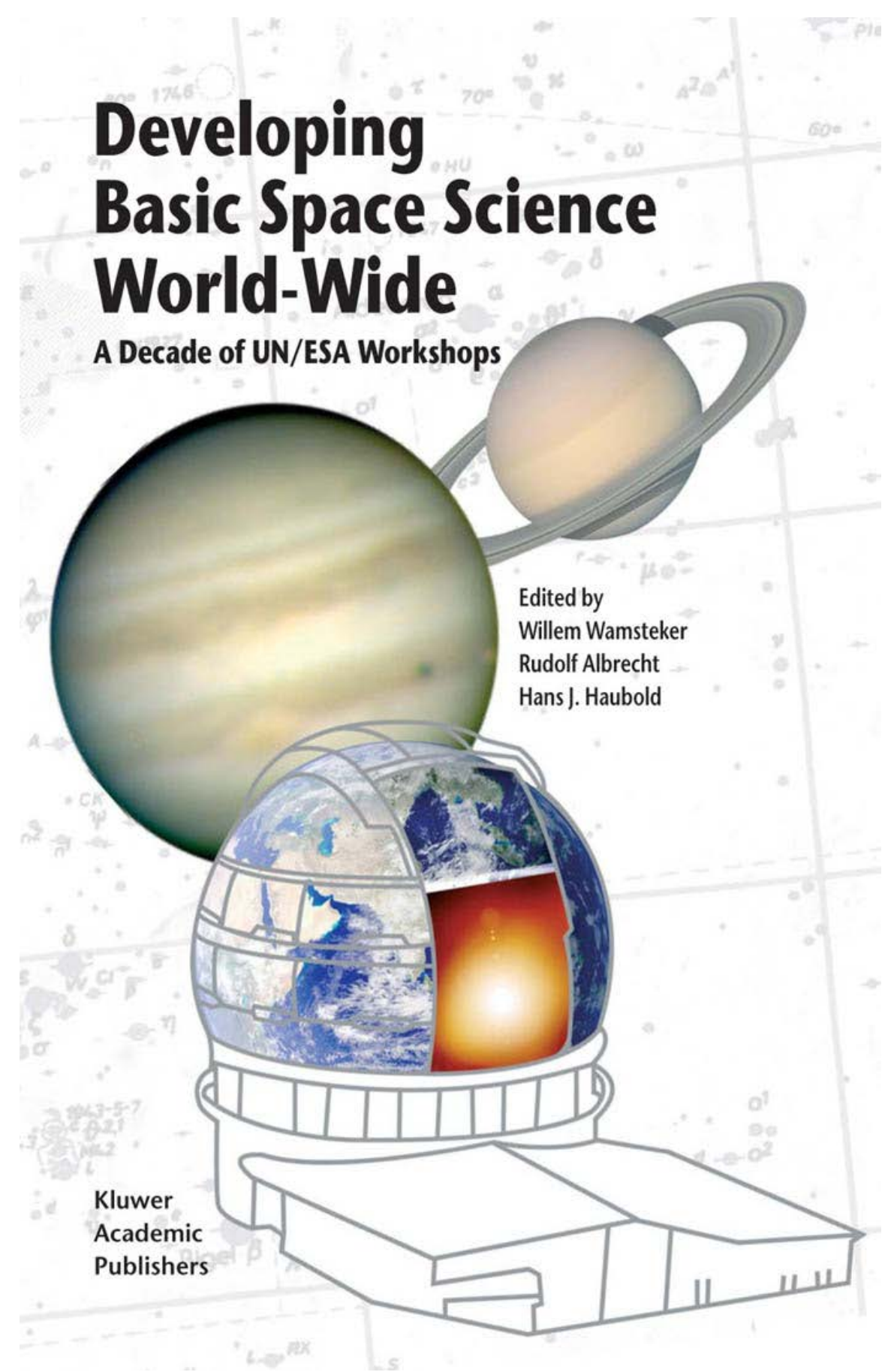

The final report on the UN/ESA Workshops on Basic Space Science 1991-2004 published by Kluwer Academic Publishers (Wamsteker, Albrecht, \& Haubold, 2004): http://www.unoosa.org/oosa/en/ourwork/psa/bssi/index.html.

Under the leadership of Professor K. Yumoto, the International Center for Space Weather Science and Education at Kyushu University, Fukuoka, Japan (www.serc.kyushu-u.ac.jp/index_e.html), was established through the basic space science initiative in 2012. The Centre for Basic Space Research, led by Professor P.N. Okeke at the University of Nigeria in Nsukka, was established in Nigeria 


\section{Studies in Space Policy}

B.J. Thompson

N. Gopalswamy

J.M. Davila

H.J. Haubold

Editors

\section{Putting the "I" in IHY}

The United Nations Report for the International Heliophysica Year 2007

SpringerWien NewYork
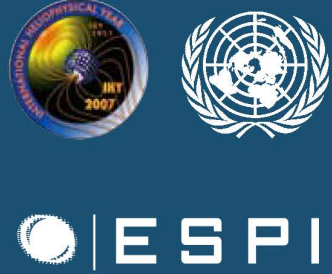

European Space Policy Institute

The final report on the 2005-2009 UN/NASA Workshops on the International Heliophysical Year 2007 (IHY 2007) published by Springer (Thompson et al., 2009):

http://www.unoosa.org/oosa/en/ourwork/psa/bssi/ihy2007.html.

(http://www.unn.edu.ng/centres/centre-basic-space-research). The Centre for Mathematical and Statistical Sciences, led by Professor A.M. Mathai and located in Kerala, India, supported all basic space science workshops (http://www.cmsintl.org).

Activities of basic space science initiative were also coordinated with the Regional Centres for Space Science and Technology Education, affiliated to the United Nations (http://www.unoosa.org/oosa/en/SAP/centres/index.html) and 
the International Committee on Global Navigation Satellite Systems (http://www.unoosa.org/oosa/en/SAP/gnss/icg.html).

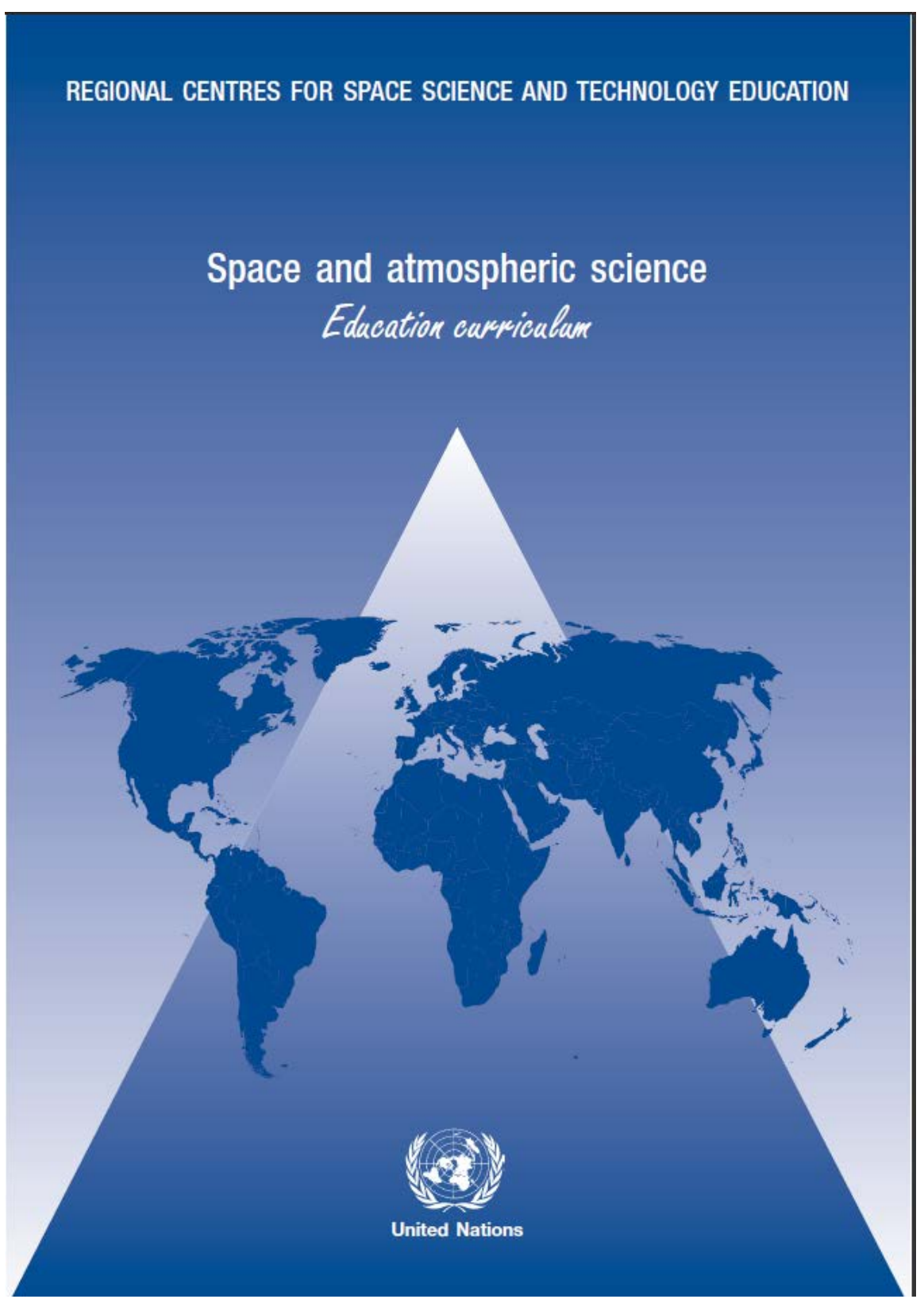

The Education Curriculum for Space and Atmospheric Science, developed in UN workshops 1998-2004 for implementation by the UN-affiliated Regional Centres for Space Science and Technology Education, located in Brazil, China, India, Jordan, Mexico, Morocco, and Nigeria:

http://www.unoosa.org/oosa/en/ourwork/psa/regional-centres/study_curricula.html

International Heliophysical Year 2007 (IHY 2007) and International Year of Astronomy 2009 (IYA 2009)

In 2007, a number of major anniversaries occurred, among them the 50th anniversary of the International Geophysical Year, the launch of Sputnik 1, and the 
50th session of the United Nations Committee on the Peaceful Uses of Outer Space (UNCOPUOS). Particularly IHY 2007 was an opportunity to 1) advance the understanding of the fundamental heliophysical processes that govern the Sun, Earth, and heliosphere, 2) continue the tradition of international research and advancing the legacy of IHY 1957, and 3) demonstrate the beauty, relevance and significance of space and Earth science to the world (http://ihy2007.org). Observing and implementing the mission and vision of IHY 2007, the basic space science initiative, in cooperation with ESA, NASA, JAXA, COSPAR, IAU, and the IHY Secretariat, hold international workshops in the United Arab Emirates in 2005 (http://www.ihy.uaeu.ac.ae/), in India in 2006 (http://www.iiap.res.in/ihy), in Japan in 2007 (http://solarwww.mtk.nao.ac.jp/UNBSS_Tokyo07/), and in Bulgaria in 2008 (http://newserver.stil.bas.bg/SUNGEO). The starting date of IHY 2007 was set to February 19, 2007. On that date, during the session of the Scientific and Technical Subcommittee of UNCOPUOS, the IHY kick-off included an IHY exhibit, press briefing, and an opening ceremony in the United Nations Office Vienna (http://ihy2007.org). The regional coordinators, Steering Committee members, and Advisory Committee members participated in the IHY kick-off event. The Austrian Academy of Sciences hosted a one-day symposium on IHY 2007 in Vienna on 20 February 2007.

The workshop for 2009 was hosted by the Republic of Korea (http://ihy.kasi.re.kr/meeting.php). This workshop also covered thematic areas as pursued by the International Year of Astronomy 2009

(http://www.astronomy2009.org). The basic space science initiative contributed to the Astronomy for the Developing World: Strategic Plan 2010-2020 (http://iau.org/static/education/strategicplan_2010-2020.pdf).

\section{Astronomical Telescopes Donated to Developing Countries through the Official Development Assistance Programme of Japan}

In order to promote education and research in developing nations, the Government of Japan has provided developing nations with high-grade equipment under the framework of the Official Development Assistance (ODA) cooperation programme since 1982 (see Table 1). Under this cooperation programme, astronomical instruments have been donated to seven developing nations. The instruments donated included university-level reflecting telescopes together with various accessories. Table 2 describes ODA donations with the assistance of the Japan International Cooperation Agency (JICA) and the cooperation with the Programme on Space Applications of the Office for Outer Space Affairs of the United Nations (OOSA).

The number of science students in developing nations is rapidly increasing. In addition, selected students attend Ph.D. courses at universities or science institutes in order to further pursue higher education and research. Many of these scholars are aware of the fact that the present age is called the "space age" and 
become therefore interested in the subject of space science and technology.

Similarly, the number of highly educated professionals in astronomy is also steadily increasing in developing nations; however, many developing nations do not have the adequate astronomical equipment so urgently needed for education and research purposes that such professionals could use. One example of the need to support cooperation programmes providing adequate astronomical equipment to developing nations is that old-fashioned refracting telescopes are still used in a good number of nations. There is still a great lack of modern high-grade reflecting telescopes of higher quality and better resolution that could be used to better observe astronomical phenomena.

Table 1. UNBSSI astronomical telescopes projects.

\begin{tabular}{|c|c|c|c|c|c|c|}
\hline & Receiving Institution & Location & Model & Option & Country & Year \\
\hline 1. & Science Centre & Singapore & 40-cm Reflector & & Singapore & 1987 \\
\hline 2. & $\begin{array}{l}\text { Bosscha Observatory Institute of } \\
\text { Technology }\end{array}$ & $\begin{array}{l}\text { Bandung, Lembang, } 40391 \text { Java, } \\
\text { Indonesia }\end{array}$ & $\begin{array}{c}45-\mathrm{cm} \\
\text { Cassegrain }\end{array}$ & $\begin{array}{l}\text { Photoelectric } \\
\text { photometer, spectrograph }\end{array}$ & Indonesia & 1988 \\
\hline 3. & Chulalongkorn University & $\begin{array}{l}\text { Physics Department Faculty of } \\
\text { Science Bangkok 10330, } \\
\text { Thailand }\end{array}$ & $\begin{array}{c}45-\mathrm{cm} \\
\text { Cassegrain }\end{array}$ & $\begin{array}{l}\text { Photoelectric } \\
\text { photometer, spectrograph }\end{array}$ & Thailand & 1989 \\
\hline 4. & $\begin{array}{l}\text { Arthur C. Clark Center for } \\
\text { Modern Technologies }\end{array}$ & $\begin{array}{l}\text { Colombo, Katubedda Moratuwa, } \\
\text { Sri Lanka }\end{array}$ & $\begin{array}{c}45-\mathrm{cm} \\
\text { Cassegrain }\end{array}$ & $\begin{array}{l}\text { Photoelectric } \\
\text { photometer, spectrograph }\end{array}$ & Sri Lanka & 1995 \\
\hline 5. & $\begin{array}{l}\text { Facultad Politecnica Asuncion } \\
\text { University }\end{array}$ & $\begin{array}{l}\text { Campus Universitario, } \\
\text { Observatorio, Astronomico, San } \\
\text { Lorenzo Asunción, Paraguay }\end{array}$ & $\begin{array}{l}45-\mathrm{cm} \\
\text { Cassegrain }\end{array}$ & $\begin{array}{l}\text { Photoelectric } \\
\text { photometer, } \\
\text { charge-coupled device }\end{array}$ & Paraguay & 1999 \\
\hline 6. & $\begin{array}{l}\text { Philippine Atmoshperic, } \\
\text { Geophysical and Astronomical } \\
\text { Services Administration }\end{array}$ & $\begin{array}{l}1424 \text { ATB Bldg., Quezon } \\
\text { Avenue, } 1104 \text { Quezon City, } \\
\text { Philippines }\end{array}$ & $\begin{array}{c}45-\mathrm{cm} \\
\text { Cassegrain }\end{array}$ & $\begin{array}{l}\text { Photoelectric } \\
\text { photometer, spectrograph }\end{array}$ & Philippines & 2000 \\
\hline 7. & $\begin{array}{l}\text { Cerro Calan Astronomical } \\
\text { Observatory Universidad de } \\
\text { Chile Departamento de } \\
\text { Astronomia }\end{array}$ & Casilla 36-D, Santiago, Chile & $\begin{array}{l}\text { 45-cm } \\
\text { Cassegrain }\end{array}$ & Charge-coupled device & Chile & 2001 \\
\hline
\end{tabular}

\section{Planetarium Equipment Donated to Developing Countries through the Official Development Assistance Programme of Japan}

Planetariums are important tools for education in astronomy. Nevertheless, only a limited number of developing nations have available planetariums located in their capital cities. On the other hand, industrialized nations have built a considerable number of planetariums that are used for space education not only in their capital cities, but also in villages, schools, and other places.

In order to promote education in developing nations, the Government of Japan has provided developing nations with equipment under the framework of the Official Development Assistance (ODA) cooperation programme since 1982 (see Table 2). Under cooperation programme, planetarium instruments have been donated to 20 developing nations. The instruments donated included complete planetariums used for educational purposes together with various accesso- 
ries. Table 1 describes the ODA donations provided with the assistance of the Japan International Cooperation Agency (JICA) and the cooperation with the Programme on Space Applications of the Office for Outer Space Affairs of the United Nations (OOSA).

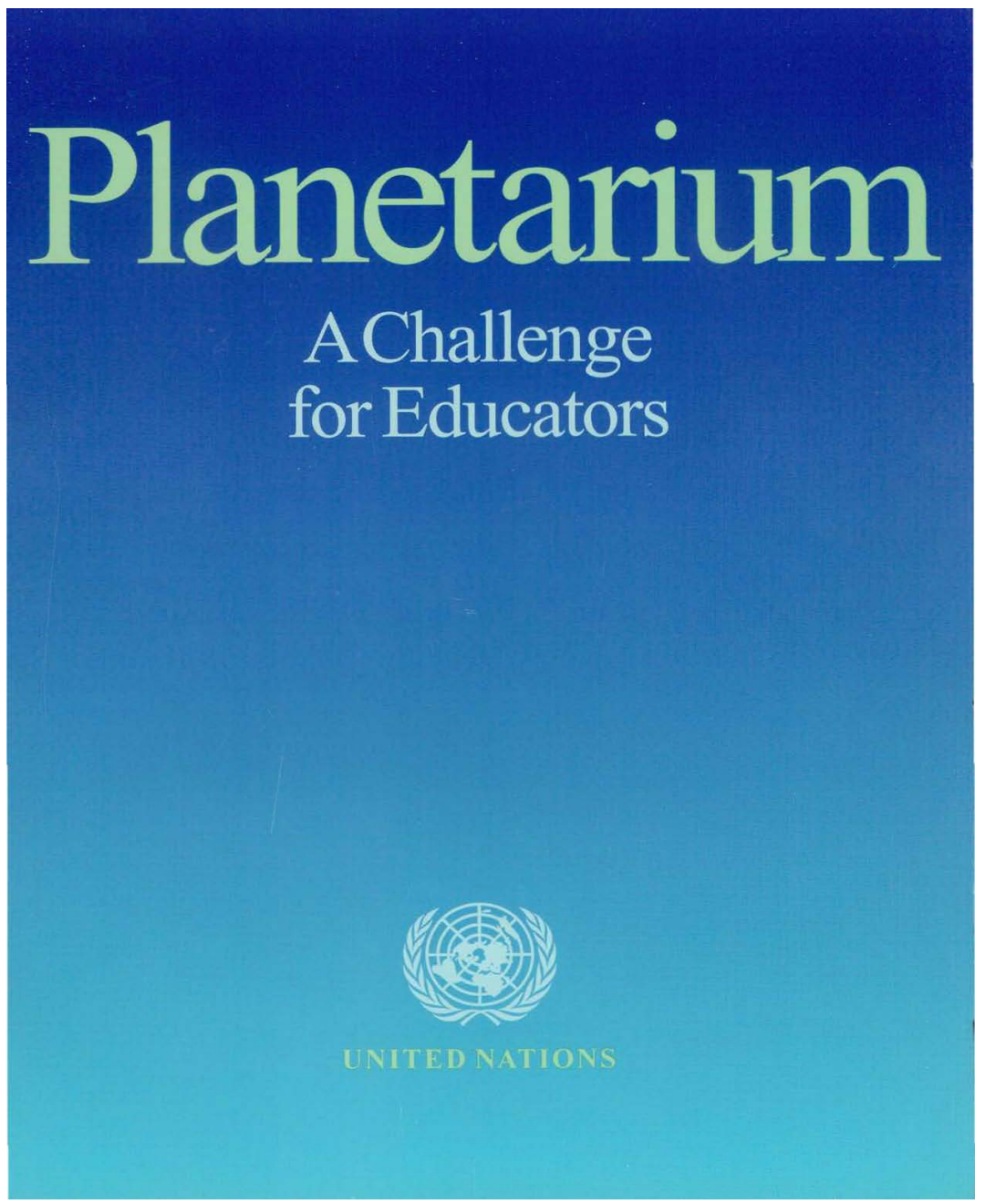

The Planetariums guidebook, developed in 1992 as part of the UN/ESA Basic Space Science Workshops, for the establishment of planetariums in developing nations through support by Japan (Smith \& Haubold, 1992):

http://www.unoosa.org/oosa/en/ourwork/psa/bssi/workshops.html.

Table 2. UNBSSI planetariums projects.

\begin{tabular}{|c|c|c|c|c|c|c|c|}
\hline & Receiving Institution & Location & Model & $\begin{array}{l}\text { Dome diameter } \\
\quad(\text { metres })\end{array}$ & Seats & Country & Year \\
\hline 1. & Pagoda Cultural Center & Yangon, Myanmar & GX & 12 & .. & Myanmar & 1986 \\
\hline 2. & $\begin{array}{l}\text { Haya Cultural Centre for } \\
\text { Child Development }\end{array}$ & Post. B. 35022, Amman, Jordan & GEII-T & 6.5 & .. & Jordan & 1989 \\
\hline 3. & $\begin{array}{l}\text { National Planetarium Space } \\
\text { Science Education Center }\end{array}$ & $\begin{array}{l}53 \text { Jalan Perdana, } 50480 \text { Kuala } \\
\text { Lumpur, Malaysia }\end{array}$ & Minolta Infinium $\beta$ & 20 & 213 & Malaysia & 1989 \\
\hline 4. & Planetarium & $\begin{array}{l}\text { Padre Burgos St., Ermita, Rizal Park, } \\
2801 \text { Manila, Philippines }\end{array}$ & $\begin{array}{l}\text { GM-15s auxiliary } \\
\text { projectors }\end{array}$ & 16 & 310 & Philippines & 1990 \\
\hline
\end{tabular}




\begin{tabular}{|c|c|c|c|c|c|c|c|}
\hline 5. & $\begin{array}{l}\text { Meghnand Saha } \\
\text { Planetarium }\end{array}$ & $\begin{array}{l}\text { University of Burdwan, Golapbag } \\
\text { Burdwan-713104, West Bengal, India }\end{array}$ & GS-AT & 8.5 & 90 & India & 1993 \\
\hline 6. & $\begin{array}{l}\text { Planetario de la Ciudad de } \\
\text { Buenos Aires "Galileo } \\
\text { Galilei" }\end{array}$ & $\begin{array}{l}\text { Av. Sarmiento y Belisario Roldán, s/n } \\
\text { C1425FHA, Buenos Aires, Argentina }\end{array}$ & Auxiliary projectors &.. & 345 & Argentina & 1993 \\
\hline 7. & Planetario de la Ciudad & $\begin{array}{l}\text { Intendencia Municipal de } \\
\text { Montevideo, Rivera 3245, } 11600 \\
\text { Montevideo, Uruguay }\end{array}$ & Auxiliary projectors &.. & .. & Uruguay & 1994 \\
\hline 8. & $\begin{array}{l}\text { Ho-Chi Minh Memorial } \\
\text { Culture Hall Vinh City } \\
\text { Planetarium }\end{array}$ & $\begin{array}{l}\text { Vinh University, No. } 6 \text { Le Mao } \\
\text { Street, Vinh City, Nghee An } \\
\text { Province, Viet Nam }\end{array}$ & GS & 8.5 & 80 & Viet Nam & 1998 \\
\hline 9. & Planetarium & $\begin{array}{l}\text { Science Center for Education, } 928 \\
\text { Sukhumvit Road, Klong toey, } \\
\text { Bangkok, } 10110 \text { Thailand }\end{array}$ & Auxiliary projectors &.. &.. & Thailand & 1998 \\
\hline 10. & Planetarium & $\begin{array}{l}\text { Ministry of Science and Technology, } \\
255 \text { Stanley Wijesundara, Mawatha, } \\
\text { Colombo 7, Sri Lanka }\end{array}$ & Auxiliary projectors &.. &.. & Sri Lanka & 1998 \\
\hline 11. & $\begin{array}{l}\text { Tamilnadu Science and } \\
\text { Technology Centre Anna } \\
\text { Science Centre Planetarium }\end{array}$ & $\begin{array}{l}\text { Pudukkottai National Highway, } \\
\text { Near Tiruchirappalli Airport, } \\
\text { Tiruchirappalli } 620 \text { 007, India }\end{array}$ & GS & 8.5 & 90 & India & 1998 \\
\hline 12. & Planetarium & $\begin{array}{l}\text { City Park, ul. Chamzy 6, Tashkent, } \\
\text { Uzbekistan }\end{array}$ & .. &. &.. & Uzbekistan & 2000 \\
\hline 13. & $\begin{array}{l}\text { Planetario Padre } \\
\text { Buenaventura Suárez S.J. }\end{array}$ & Oliva No. 479, Asunción, Paraguay & EX-3 & 5 & 23 & Paraguay & 2001 \\
\hline 14. & Planetario Municipal & $\begin{array}{l}\text { Florencia Astudillo y Alfonso } \\
\text { Cordero, Parque de la Madre, } \\
\text { Cuenca, Ecuador }\end{array}$ & .. &.. & 70 & Equador & 2002 \\
\hline 15. & $\begin{array}{l}\text { El Pequeño Sula, Museo } \\
\text { para la Infancia of the City } \\
\text { Hall of San Pedro Sula }\end{array}$ & $\begin{array}{l}\text { Bulevar del Sur, Contiguo al } \\
\text { Gimnasio Municipal, San Pedro } \\
\text { Sula, Honduras C.A. }\end{array}$ & GS-T & 8.5 &.. & Honduras & 2003 \\
\hline 16. & $\begin{array}{l}\text { National Costa Rica } \\
\text { University }\end{array}$ & San José, Costa Rica & GS-S & 8.5 & 40 & Costa Rica & 2003 \\
\hline 17. & $\begin{array}{l}\text { Laboratorio Central del } \\
\text { Instituto Geofisico }\end{array}$ & $\begin{array}{l}\text { Calle Badajoz 169-171, IV Etapa } \\
\text { Mayorazgo, ATE, Lima 03, Perú }\end{array}$ & GS-T & 7.5 &.. & Perú & $\begin{array}{l}\text { Scheduled } \\
\text { for } 2007\end{array}$ \\
\hline 18. & $\begin{array}{l}\text { National Astronomical } \\
\text { Observatory of Tarija }\end{array}$ & $\begin{array}{l}\text { Loc. Santa Ana Tarija, P.O. Box } 346 \text {, } \\
\text { Bolivia }\end{array}$ & GS-S & 8.5 &.. & Bolivia & $\begin{array}{l}\text { Scheduled } \\
\text { for } 2008\end{array}$ \\
\hline 19. & National History Museum & Havana, Cuba &.. &.. &.. & Cuba & $\begin{array}{l}\text { Scheduled } \\
\text { for } 2007\end{array}$ \\
\hline 20. & $\begin{array}{l}\text { Tin Marín Children’s } \\
\text { Museum }\end{array}$ & $\begin{array}{l}\text { Sexta Decima Calle Poniente, Centro } \\
\text { Gimnacio Nacional y Parque } \\
\text { Cuscatlan, San Salvador, El Salvador }\end{array}$ & GE-II & 6.5 &.. & El Salvador & 2007 \\
\hline
\end{tabular}

\section{Countries Hosting Instruments of the International Space Weather Initiative Provided by Armenia, Brazil, France, Israel, Japan, Switzerland, and the United States of America}

A major thrust of IHY 2007 and ISWI was to deploy arrays of small, inexpensive instruments such as magnetometers, radio telescopes, GPS receivers, all-sky cameras, etc. around the world to allow global measurements of ionospheric and heliospheric phenomena. The small instrument programme was envisioned as a partnership between instrument providers and instrument hosts in respective nations (see Listing 1). The lead scientist is providing the instruments (or fabri- 
cation plans for instruments) in the array; the host nation provides human resources, facilities, and operational support to obtain data with the instrument, typically at a local university. Financial resources were not available through IHY and ISWI to build the instruments; these had to be obtained through the normal proposal channels. All instrument operational support for local scientists, facilities, data acquisition, etc. is provided by the host nation. The IHY and ISWI facilitated the deployment of several of these networks world-wide. Existing data bases and relevant software tools were identified to promote space science activities in developing nations. Extensive data on space science had been accumulated by a number of space missions. Similarly, long-term data bases are available from ground-based observations.

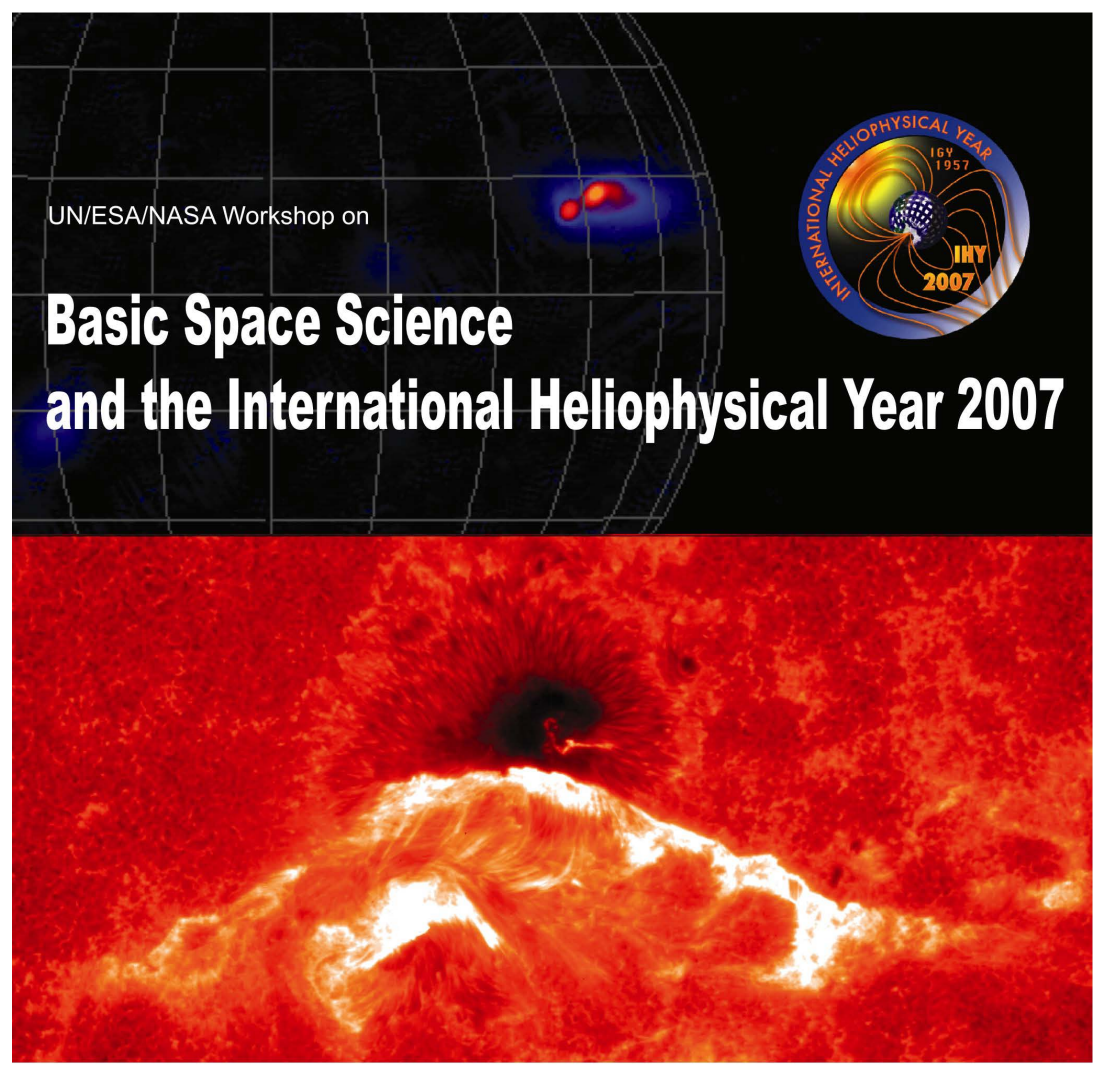

\section{National Astronomical Observatory of Japan Mitaka, Tokyo}

\section{8-22 June, 2007}

Under the Auspices of

Ministry of Education, Culture, Sports, Science and Technology Ministry of Foreign Affairs
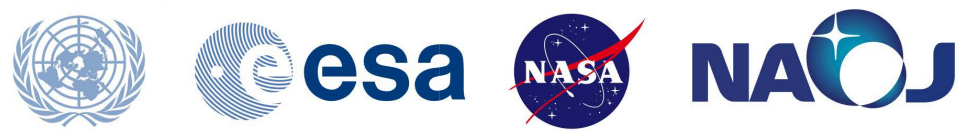

The poster for the 2007 UNESA/NASA/JAXA Workshop, hosted by the Government of Japan at the occasion of IHY 2007:

http://solarwww.mtk.nao.ac.jp/UNBSS_Tokyo07/. 


\section{Listing 1}

01. Algeria (7) $A M B E R(1), A W E S O M E(1), C H A I N(1), G P S \_A f r i c a(1)$, $M A G \_A f r i c a(1), \operatorname{SID}(2)$

02. Antarctica (2) AWESOME(1), SID(1)

03. Argentina (1) $S A V N E T(1)$

04. Armenia (3) $S E V A N(3)$

05. Australia (18) CALLISTO(2), GMDN(1), MAGDAS(11), OMTIs(1), SID(3)

06. Austria (3) CALLISTO(1), SID(2)

07. Azerbaijan (3) AWESOME(1), SID(2)

08. Bangladesh (1) $\operatorname{SID}(1)$

09. Belgium (1) CALLISTO(1)

10. Benin (1) GPS_Africa(1)

11. Bosnia-Herzegovina (1) $\operatorname{SID}(1)$

12. Botswana (1) GPS_Africa(1)

13. Brazil (24) CALLISTO(2), CSSTE(1), GMDN(1), MAGDAS(2), RENOIR(2), SAVNET(6), SCINDA(3), SID(7)

14. British Virgin Islands (1) $\operatorname{SID(1)}$

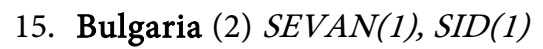

16. Burkina Faso (3) GPS_Africa(2), SID(1)

17. CHINA (3) $\operatorname{SID}(3)$

18. Cameroon (2) $A M B E R(1), S C I N D A(1)$

19. Canada (20) MAGDAS(1), OMTIS(2), SID(17)

20. Cape Verde (2) GPS_Africa(1), SCINDA(1)

21. Central African Republic (1) $M A G \_A f r i c a(1)$

22. Chile (1) SCINDA(1)

23. China (26) $\operatorname{SID}(26)$

24. Colombia (8) $S C I N D A(1)$, SID(7)

25. Congo (7) $\operatorname{SCINDA(3),~} \operatorname{SID}(4)$

26. Costa Rica (1) CALLISTO(1)

27. Cote d'Ivoire (4) MAGDAS(1), MAG_Africa(2), SCINDA(1)

28. Croatia (6) $\operatorname{SEVAN(1),SID(5)}$

29. Cypress (1) $\operatorname{SID}(1)$

30. Czech Republic (2) CALLISTO(1), SID(1)

31. D Rep of Congo (2) $\operatorname{SID}(2)$

32. Denmark (2) $\operatorname{SID}(2)$

33. Djibouti (1) $S C I N D A(1)$

34. Ecuador (1) MAGDAS(1)

35. Egypt (9) AWESOME(1), CALLISTO(1), CIDR(1), MAGDAS(2), $\operatorname{SCINDA(1),SID(3)}$

36. England (1) $\operatorname{SID(1)}$

37. Ethiopia (20) AMBER(1), AWESOME(1), MAGDAS(1), MAG_Africa(1), SCINDA(2), SID(14)

38. Fiji (1) $A W E S O M E(1)$ 
39. Finland (2) CALLISTO(2)

40. France (4) $\operatorname{SID}(4)$

41. Gabon (2) GPS_Africa(2)

42. Germany (26) CALLISTO(2), SID(24)

43. Ghana (1) GPS_Africa(1)

44. Greece (6) AWESOME(1), SID(5)

45. Guyana (2) $S C I N D A(1), \operatorname{SID}(1)$

46. India (25) $A W E S O M E(2), C A L L I S T O(4), \operatorname{CSSTE}(1), M A G D A S(1)$, $\operatorname{SEVAN}(1), \operatorname{SID}(16)$

47. Indonesia (10) $M A G D A S(8), \operatorname{SID}(2)$

48. Ireland (14) AWESOME(1), CALLISTO(4), SID(9)

49. Israel (4) AWESOME(1), ULF_ELF_VLF(3)

50. Italy (41) CALLISTO(2), MAGDAS(1), SID(38)

51. Japan (13) $C H A I N(1), G M D N(1), M A G D A S(7), O M T I s(4)$

52. Jordan (1) $\operatorname{CSSTE}(1)$

53. Kazakhstan (1) CALLISTO(1)

54. Kenya (8) CALLISTO(1), GPS_Africa(1), MAGDAS(1), SCINDA(2), $\operatorname{SID}(3)$

55. Korea (2) $\operatorname{SID}(2)$

56. Kuwait (1) GMDN(1)

57. Lebanon (11) $\operatorname{SID}(11)$

58. Libya (3) AWESOME(2), SID(1)

59. Madagascar (1) $M A G_{-}$Africa(1)

60. Malaysia (23) AWESOME(1), CALLISTO(3), MAGDAS(2), OMTIs(1), $\operatorname{SID}(16)$

61. Mali (4) GPS_Africa(2), MAG_Africa(2)

62. Mauritius (3) CALLISTO(3)

63. Mexico (17) CALLISTO(1), CSSTE(1), SAVNET(1), SID(14)

64. Micronesia (1) $M A G D A S(1)$

65. Mongolia (13) CALLISTO(2), MAGDAS(1), SID(10)

66. Morocco (22) AWESOME(1), CSSTE(1), GPS_Africa(19), RENOIR(1)

67. Mozambique (4) GPS_Africa(1), MAGDAS(1),SID(2)

68. Namibia (4) AMBER(1), GPS_Africa(1), MAG_Africa(1), SID(1)

69. Netherlands (2) $\operatorname{SID}(2)$

70. New Zealand (4) SID(4)

71. Niger (1) GPS_Africa(1)

72. Nigeria (47) $A M B E R(1), \operatorname{CSSTE}(1), M A G D A S(3), S C I N D A(4), \operatorname{SID}(38)$

73. Norway (1) $\operatorname{OMTIS}(1)$

74. Pakistan (3) SID(3)

75. Peru (8) $C H A I N(1), C I D R(1), M A G D A S(2), S A V N E T(3), S C I N D A(1)$

76. Philippines (8) $M A G D A S(6), S C I N D A(1), S I D(1)$

77. Poland (1) AWESOME(1)

78. Portugal (3) SID(3) 
79. Rep of Congo (1) SID(1)

80. Republic of the Marshal Islands (1) $\operatorname{SCINDA(1)}$

81. Romania (3) $\operatorname{SID}(3)$

82. Russia (13) CALLISTO(1), MAGDAS(9), OMTIs(2), SID(1)

83. Sao Tome and Principe (2) GPS_Africa(1), SCINDA(1)

84. Scotland (1) $\operatorname{SID(1)}$

85. Senegal (3) GPS_Africa(1), MAG_Africa(1), SID(1)

86. Serbia (2) AWESOME(1), SID(1)

87. Slovakia (4) CALLISTO(1), SEVAN(1), SID(2)

88. Slovenia (1) $\operatorname{SID}(1)$

89. South Africa (26) GPS_Africa(7), MAGDAS(2), MAG_Africa(2),

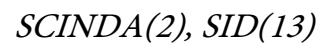

90. South Korea (2) CALLISTO(2)

91. Spain (4) CALLISTO(2), MAG_Africa(1), SID(1)

92. Sri Lanka (2) CALLISTO(1), SID(1)

93. Sudan (1) $M A G D A S(1)$

94. Sweden (3) $\operatorname{SID}(3)$

95. Switzerland (8) CALLISTO(5), SID(3)

96. Taiwan (4) MAGDAS(1), SID(3)

97. Tanzania (2) MAGDAS(1), SCINDA(1)

98. Thailand (6) OMTIs(1), SID(5)

99. Tunisia (8) AWESOME(1), SID(9)

100. Turkey (3) AWESOME(1), SID(2)

101. UAE (1) AWESOME(1)

102. UK (20) CALLISTO(1), MAG_Africa(1), SCINDA(2), SID(16)

103. URUGUAY (4) $\operatorname{SID}(4)$

104. USA (270) AWESOME(2), CALLISTO(3), CIDR(9), MAGDAS(2), SCINDA(2), SID(252)

105. US Virgin Islands (2) $S I D(2)$

106. Uganda (5) $\operatorname{SCINDA(1),SID(4)}$

107. Ukraine (1) CALLISTO(1)

108. Uruguay (3) $\operatorname{SID(3)}$

109. Uzbekistan (3) AWESOME(1), SID(2)

110. Venezuela (2) $\operatorname{SID}(2)$

112. Viet Nam (3) AWESOME(1), MAGDAS(1), SID(1)

112. Zambia (3) $M A G D A S(1), \operatorname{SID}(2)$

LEGEND

AMBER African Meridian B-field Education and Research

AWESOME Atmospheric Weather Education System for Observation and Modelling of Effects

CALLISTO Compound Astronomical Low-cost Low-frequency Instrument for Spectroscopy and Transportable Observatory

CHAIN Continuous $\mathrm{H}$-alpha Imaging Network 


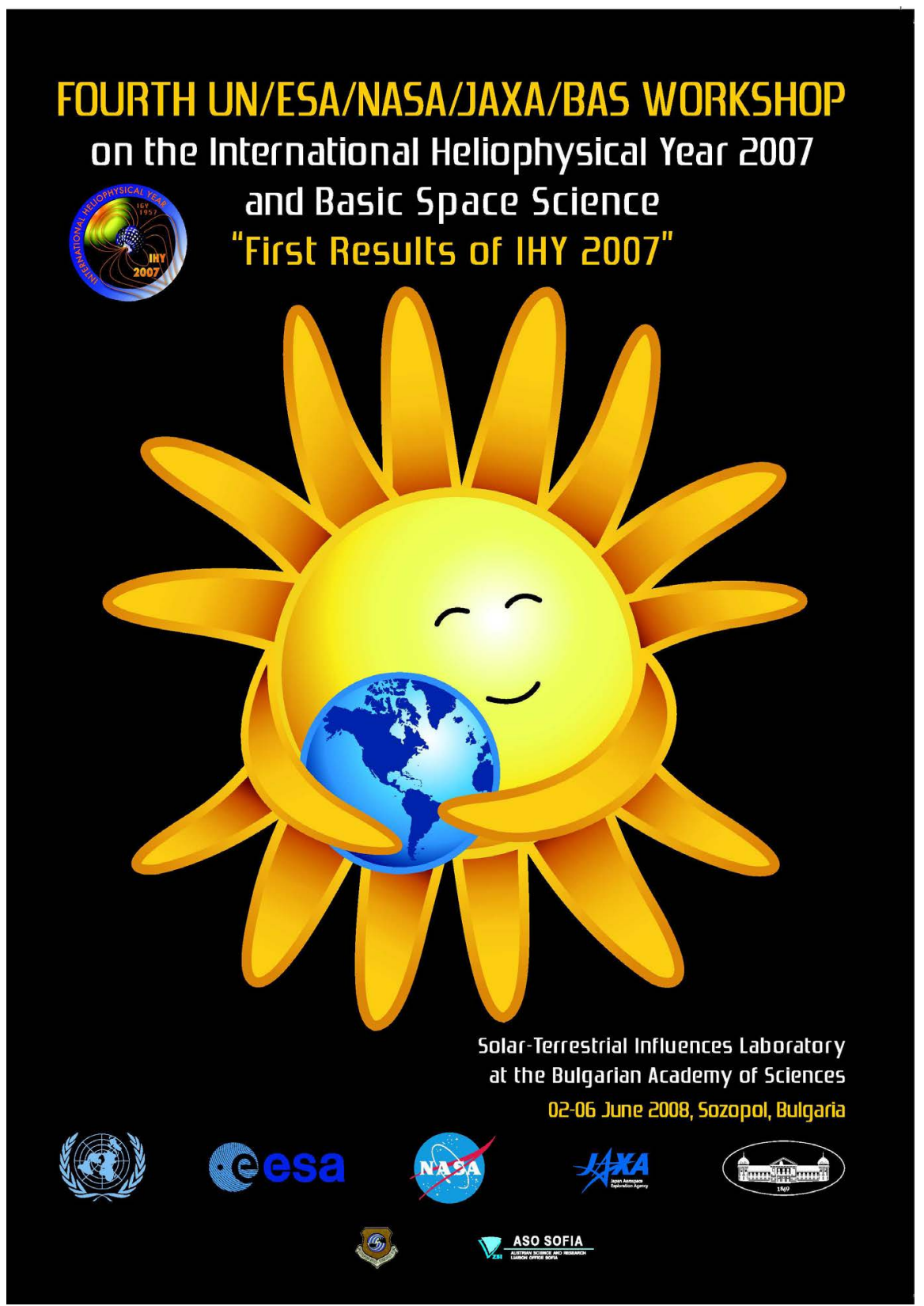

The poster of the 2008 UN/ESA/NASA/JAXA Workshop, hosted by the Government of Bulgaria: http://www.stil.bas.bg/UNBSS-IHY/.

CIDR Coherent Ionospheric Doppler Radar CSSTE Centres for Space Science and Technology Education GMDN Global Muon Detector Network GPS Africa African Dual Frequency GPS Network MAGDAS Magnetic Data Acquisition System MAG Africa Magnetometers in Africa OMTIs Optical Mesosphere Thermosphere Imager RENOIR Remote Equatorial Night time Observatory for Ionospheric Regions SAVNET South America Very Low frequency Network 
SCINDA Scintillation Network Decision Aid

SEVAN Space Environment Viewing and Analysis Network

SID Sudden Ionospheric Disturbance Monitor

ULF_ELF_VLF ULF/ELF/VLF network

Current distribution of the International Space Weather Initiative instrument arrays as operational data sources

Distribution of instruments by country

Centres for Space Science and Technology Education (CSSTE)

6 centres, hosted in 6 countries

Brazil (1), India (1), Jordan (1), Mexico (1), Morocco (1), Nigeria (1),

African Meridian B-field Education and Research (AMBER)

5 instruments, hosted in 5 countries

Algeria (1), Cameroon (1), Ethiopia (1), Namibia (1), Nigeria (1),

Atmospheric Weather Education System for Observation and Modelling of Effects (AWESOME)

24 instruments, hosted in 21 countries

Algeria (1), Antarctica (1), Azerbaijan (1), Egypt (1), Ethiopia (1), Fiji (1), Greece (1), India (2), Ireland (1), Israel (1), Libya (2), Malaysia (1), Morocco (1), Poland (1), Serbia (1), Tunisia (1), Turkey (1), UAE (1), USA (2), Uzbekistan (1), Viet Nam (1),

Compound Astronomical Low-cost Low-frequency Instrument for Spectroscopy and Transportable Observatory (CALLISTO)

51 instruments, hosted in 27 countries

Australia (2), Austria (1), Belgium (1), Brazil (2), Costa Rica (1), Czech Republic (1), Egypt (1), Finland (2), Germany (2), India (4), Ireland (4), Italy (2), Kazakhstan (1), Kenya (1), Malaysia (3), Mauritius (3), Mexico (1), Mongolia (2), Russia (1), Slovakia (1), South Korea (2), Spain (2), Sri Lanka (1), Switzerland (5), UK (1), USA (3), Ukraine (1),

Continuous $\mathrm{H}$-alpha Imaging Network (CHAIN)

3 instruments, hosted in 3 countries

Algeria (1), Japan (1), Peru (1),

Coherent Ionospheric Doppler Receivers (CIDR)

11 instruments, hosted in 3 countries

Egypt (1), Peru (1), USA (9),

Global Muon Detector Network (GMDN)

4 instruments, hosted in 4 countries

Australia (1), Brazil (1), Japan (1), Kuwait (1),

African Dual Frequency GPS Network (GPS_Africa)

43 instruments, hosted in 16 countries

Algeria (1), Benin (1), Botswana (1), Burkina Faso (2), Cape Verde (1), Gabon (2), Ghana (1), Kenya (1), Mali (2), Morocco (19), Mozambique (1), Namibia (1), Niger (1), Sao Tome (1), Senegal (1), South Africa (7),

Magnetic Data Acquisition System (MAGDAS) 
71 instruments, hosted in 27 countries

Australia (11), Brazil (2), Canada (1), Cote d'Ivoire (1), Ecuador (1), Egypt (2),

Ethiopia (1), India (1), Indonesia (8), Italy (1), Japan (7), Kenya (1), Malaysia (2), Micronesia (1), Mongolia (1), Mozambique (1), Nigeria (3), Peru (2), Philippines (6), Russia (9), South Africa (2), Sudan (1), Taiwan (1), Tanzania (1), USA (2), Viet Nam (1), Zambia (1),

\section{Magnetometers in Africa (MAG_Africa)}

14 instruments, hosted in 11 countries

Algeria (1), Central African Rep. (1), Cote d'Ivoire (2), Ethiopia (1), Madagascar (1), Mali (2), Namibia (1), Senegal (1), South Africa (2), Spain (1), UK (1),

Optical Mesosphere Thermosphere Imager (OMTIs)

12 instruments, hosted in 7 countries

Australia (1), Canada (2), Japan (4), Malaysia (1), Norway (1), Russia (2), Thailand (1),

Remote Equatorial Night time Observatory for Ionospheric Regions (RENOIR)

3 instruments, hosted in 2 countries

Brazil (2), Morocco (1),

South America Very Low frequency Network (SAVNET)

11 instruments, hosted in 4 countries

Argentina (1), Brazil (6), Mexico (1), Peru (3),

\section{Scintillation Network Decision Aid (SCINDA)}

34 instruments, hosted in 22 countries

Brazil (3), Cameroon (1), Cape Verde (1), Chile (1), Colombia (1), Congo (3), Cote d'Ivoire (1), Djibouti (1), Egypt (1), Ethiopia (2), Guyana (1), Kenya (2), Nigeria (4), Peru (1), Philippines (1), Rep. of Marshal Islands (1), Sao Tome and Principe (1), South Africa (2), Tanzania (1), UK (2), USA (2), Uganda (1),

Space Environment Viewing and Analysis Network (SEVAN)

7 instruments, hosted in 5 countries

Armenia (3), Bulgaria (1), Croatia (1), India (1), Slovakia (1),

Sudden Ionospheric Disturbance Monitor (SID)

657 instruments, hosted in 75 countries

Algeria (2), Antarctica (1), Australia (3), Austria (2), Azerbaijan (2), Bangladesh (1), Bosnia-Herzegovina (1), Brazil (7), British Virgin Islands (1), Bulgaria (1), Burkina Faso (1), CHINA (3), Canada (17), China (26), Colombia (7), Congo (4), Croatia (5), Cypress (1), Czech Republic (1), D Rep of Congo (2), Denmark (2), Egypt (3), England (1), Ethiopia (14), France (4), Germany (24), Greece (5), Guyana (1), India (16), Indonesia (2), Ireland (9), Italy (38), Kenya (3), Korea (2), Lebanon (11), Libya (1), Malaysia (16), Mexico (14), Mongolia (10), Mozambique (2), Namibia (1), Netherlands (2), New Zealand (4), Nigeria (38), Pakistan (3), Philippines (1), Portugal (3), Rep of Congo (1), Romania (3), Russia (1), Scotland (1), Senegal (1), Serbia (1), Slovakia (2), Slovenia (1), South Africa (13), Spain (1), Sri Lanka (1), Sweden (3), Switzerland (3), Taiwan (3), Thailand 
(5), Tunisia (7), Tunisia (2), Turkey (2), UK (16), URUGUAY (4), USA (252), US Virgin Islands (2), Uganda (4), Uruguay (3), Uzbekistan (2), Venezuela (2), Viet Nam (1), Zambia (2),

ULF/ELF/VLF network (ULF_ELF_VLF)

3 instruments, hosted in 1 countries

Israel (3),

Published scientific papers based on results of the International Space Weather Initiative in the period of time from 2009-2013

\section{Listing 2}

\section{3}

1. Raulin, J.-P., G.H.Trottet, M.Kretzschmar, E.L.Macotela, A.A.Pacini, F.C.P.Bertoni, I.Dammasch Response of the low ionosphere to X-ray and Lyman-alpha solar flare emissions (2013) Journal of Geophysical Research, Article in Press (ADS) doi: 10.1029/2012JA017916

2. De La Luz, V., Raulin, J.-P., Lara, A. The Chromospheric Solar Millimeter-wave Cavity originates in the temperature minimum region (2013) Astrophysical Journal, 762 (2), art. no. 84, Article

3. Correia, E., Raulin, J.-P., Kaufmann, P., Bertoni, F., Quevedo, M.T. Inter-hemispheric analysis of daytime low ionosphere behavior from 2007 to 2011 (2013) Journal of Atmospheric and Solar-Terrestrial Physics, 92, pp. 51-58. Article

2012

4. Z.S.Hamidi, Z.Z.Abidin, Z.A.Ibrahim, C.Monstein, N.N.M.Shariff Combined Investigations of Solar Bursts Type III and V (2012) International Journal of Fundamental Physics Sciences, Vol. 2, No. 3, pp. 41-43 (ADS)

5. Z.S.Hamidi, Z.Z.Abidin, Z.A.Ibrahim, C.Monstein, N.N.M.Shariff Signal Detection Performed by Log Periodic Dipole Antenna (LPDA) In Solar Monitoring (2012) International Journal of Fundamental Physics Sciences, Vol. 2, No. 2, pp. 24-26 (ADS)

6. Z.S.Hamidi, Z.Z.Abidin, Z.A.Ibrahim, C.Monstein, N.N.M.Shariff, M.Sabaghi The Beginning Impulsive of Solar Burst Type IV Radio Emission Detection Associated with M Type Solar Flare (2012) International Journal of Fundamental Physics Sciences, Vol. 2, No. 2, pp. 32-34 (ADS)

7. Zhao, B., Wan, W., Lei, J., Wei, Y., Sahai, Y., Reinisch, B. Positive ionospheric storm effects at Latin America longitude during the superstorm of 20-22 November 2003: revisit (2012) Annales Geophysicae, Volume 30, Issue 5, 2012, pp.831-840 (ADS) doi: 10.5194/angeo-30-831-2012

8. Zerbo, J.-L., Amory-Mazaudier, C., Ouattara, F. Geomagnetism during solar cycle 23: Characteristics (2012) Journal of Advanced Research, Article in Press doi: 10.1016/j.jare.2012.08.010

9. Zerbo, J.L., Amory Mazaudier, C., Ouattara, F., Richardson, J.D. Solar wind and geomagnetism: Toward a standard classification of geomagnetic activi- 
ty from 1868 to 2009 (2012) Annales Geophysicae, 30 (2), pp. 421-426. Review 10. Zoundi C., F.Ouattara, R.Fleury, C.Amory-Mazaudier, P.Lassudrie-Duchesne Seasonal TEC variability in West Africa Equatorial Anomaly Region (2012) European Journal of Scientific Research, Vol 77 n03, pp. 309-319 (ADS)

11. Zucca, P., Carley, E.P., McCauley, J., Gallagher, P.T., Monstein, C., McAteer, R.T.J. Observations of Low Frequency Solar Radio Bursts from the Rosse Solar-Terrestrial Observatory (2012) Solar Physics, 280 (2), pp. 591-602. Article doi: $10.1007 / \mathrm{s} 11207-012-9992-\mathrm{x}$

12. Yizengaw, E., Zesta, E., Moldwin, M.B., Damtie, B., Mebrahtu, A., Valladares, C.E., Pfaff, R.F. Longitudinal differences of ionospheric vertical density distribution and equatorial electrodynamics (2012) Journal of Geophysical Research, Volume 117, Issue A7, CiteID A07312 (ADS) doi: 10.1029/2011JA017454 13. Yizengaw, E., Zesta, E., Moldwin, M.B., Damtie, B., Mebrahtu, A., Valladares, C.E., Pfaff, R.F. Longitudinal differences of ionospheric vertical density distribution and equatorial electrodynamics (2012) Journal of Geophysical Research A: Space Physics, 117 (7), art. no. A07312, Article

14. Yizengaw, Endawoke Ground-based Instrumentations in Africa and its Scientific and Societal Benefits to the region (2012) 39th COSPAR Scientific Assembly. Held 14-22 July 2012, in Mysore, India. Abstract C0.3-6-12, p.2216 (ADS)

15. Yizengaw, Endawoke, Valladares, Cesar, Moldwin, Mark, Pfaff, Robert, Zesta, Eftyhia, Damtie, Baylie, Mebrahtu, Alem Longitudinal dependence of equatorial electrodynamics and ionospheric vertical density distribution (2012) 39th COSPAR Scientific Assembly. Held 14-22 July 2012, in Mysore, India. Abstract C2.2-19-12, p.2214 (ADS)

16. Yizengaw, Endawoke, Moldwin, Mark, Pfaff, Robert, Zesta, Eftyhia, Boudouridis, Athanasios, Damtie, Baylie, Mebrahtu, Alem, Biouele, Cesar, Anad, Fatma, Hartinger, Michael ULF wave related equatorial electrojet fluctuations (2012) 39th COSPAR Scientific Assembly. Held 14-22 July 2012, in Mysore, India. Abstract PCB.1-8-12, p.2217 (ADS)

17. Yizengaw, Endawoke, Moldwin, Mark, Coster, Anthea Placing AMISR Instrument in the African sector: Why and How? (2012) 39th COSPAR Scientific Assembly. Held 14-22 July 2012, in Mysore, India. Abstract C1.1-28-12, p.2215 (ADS)

18. Vilmer, Nicole, Amory, Christine Capacity Building in Space Weather in the context of the ISWI program (2012) 39th COSPAR Scientific Assembly. Held 14-22 July 2012, in Mysore, India. Abstract H0.1-2-12, p.2094 (ADS)

19. Thiam, N., Frederic Ouattara, Gnabahou Allain, Christine Amory Mazaudier, Rolland Fleury, Patrick Lassudrie Duchesne Variation of F2 layer critical frequency with solar cycle at Dakar station (2012) Journal des Sciences (in French), Vol. 11 N 2, 16-20 (ADS)

20. Takla, E.M., Yumoto, K., Ishitsuka, J., Rosales, D., Dutra, S., Uozumi, T., 
Abe, S. Geomagnetic variations possibly associated with the Pisco earthquake on 15 August 2007, Peru (2012) Tectonophysics, 524-525, pp. 29-36. Article

21. Shin Suzuki, Kazuo Shiokawa, Yuichi Otsuka, Seiji Kawamura, Yasuhiro Murayama Evidence of gravity wave ducting in the mesopause region from airglow network observations (2012) Geophys. Res. Lett., Article in press (ADS) doi: 10.1029/2012GL054605

22. Shiokawa, K., Mori, M., Otsuka, Y., Oyama, S., Nozawa, S. Motion of high-latitude nighttime medium-scale traveling ionospheric disturbances associated with auroral brightening (2012) Journal of Geophysical Research A: Space Physics, 117 (10), art. no. A10316, Article

23. Salut, M.M., Abdullah, M., Graf, K.L., Cohen, M.B., Cotts, B.R.T., Kumar, S. Long recovery VLF perturbations associated with lightning discharges (2012) Journal of Geophysical Research A: Space Physics, 117 (8), art. no. A08311, Article

24. Shimeis, A., Fathy, I., Amory-Mazaudier, C., Fleury, R., Mahrous, A.M., Yumoto, K., Groves, K. Signature of the coronal hole near the north crest equatorial anomaly over Egypt during the strong geomagnetic storm 5 April 2010 (2012) Journal of Geophysical Research A: Space Physics, 117 (7), art. no. A07309, Article

25. Singh, R., Cohen, M.B., Maurya, A.K., Veenadhari, B., Kumar, S., Pant, P., Said, R.K., Inan, U.S. Very low latitude $(\mathrm{L}=1.08)$ whistlers (2012) Geophysical Research Letters, 39 (23), art. no. L23102, Article

26. Price., C. The Schumann resonances (2012) in Lightning Electromagnetics, ISBN:978-1-84919-215-6, 974 pages, Volume 62 of IET power and energy series, ed. V. Cooray, pp.583-609 (ADS)

27. Paznukhov, V.V., Carrano, C.S., Doherty, P.H., Groves, K.M., Caton, R.G., Valladares, C.E., Seemala, G.K., Bridgwood, C.T., Adeniyi, J., Amaeshi, L.L.N., Damtie, B., D'Ujanga Mutonyi, F., Ndeda, J.O.H., Baki, P., Obrou, O.K., Okere, B., Tsidu, G.M. Equatorial plasma bubbles and L-band scintillations in Africa during solar minimum (2012) Annales Geophysicae, 30 (4), pp. 675-682. Article

28. Ouattara F. foF2 Long Term trends at Ougadougou station (2012) British Journal of Applied Science and Technlology, Vol.2 iss.3. p 240-253 (ADS)

29. Oliver, W.L., Martinis, C.R., Hickey, D.A., Wright, A.D., Amory-Mazaudier, C. A nighttime temperature maximum in the thermosphere above Saint Santin in winter (2012) Journal of Geophysical Research, Volume 117, Issue A6, CiteID A06324 (ADS) doi: 10.1029/2012JA017855

30. Otsuka, Y., Shiokawa, K., Ogawa, T. Disappearance of equatorial plasma bubble after interaction with mid-latitude medium-scale traveling ionospheric disturbance (2012) Geophysical Research Letters, 39 (14), art. no. L14105,

31. Olwendo, O.J., Baki, P., Mito, C., Doherty, P. Characterization of ionospheric GPS Total Electron Content (GPS-TEC) in low latitude zone over the Kenyan region during a very low solar activity phase (2012) Journal of Atmospheric and Solar-Terrestrial Physics, 84-85, pp. 52-61. Article 
32. Olwendo, O.J., Baki, P., Cilliers, P.J., Mito, C., Doherty, P. Comparison of GPS TEC measurements with IRI-2007 TEC prediction over the Kenyan region during the descending phase of solar cycle 23 (2012) Advances in Space Research, 49 (5), pp. 914-921. Cited 1 time. Article

33. Okoh, D., McKinnell, L.-A., Cilliers, P., Okeke, P. Using GPS-TEC data to calibrate VTEC computed with the IRI model over Nigeria (2012) Advances in Space Research, Article in Press

34. Olwendo, J.O., Cilliers, P.J., Baki, P., Mito, C. Using GPS-SCINDA observations to study the correlation between scintillation, total electron content enhancement and depletions over the Kenyan region (2012) Advances in Space Research, 49 (9), pp. 1363-1372. Article

35. Ouattara, F., Gnabahou, D.A., Amory Mazaudier, C. Seasonal, diurnal, and solar-cycle variations of electron density at two West Africa equatorial ionization anomaly stations (2012) International Journal of Geophysics, 2012, art. no. 640463, Cited 1 time. Article

36. Ouattara, F., Amory-Mazaudier, Christine Statistical study of the equatorial F2 layer critical frequency at Ouagadougou during solar cycles 20, 21 and 22, using Legrand and Simon's classification of geomagnetic activity (2012) Journal of Space Weather and Space Climate, Volume 2, id.A19, 10 pp. (ADS) doi: $10.1051 /$ swsc/2012019

37. Okoh, D., Eze, A., Adedoja, O., Okere, B., Okeke, P.N. A comparison of IRI-TEC predictions with GPS-TEC measurements over Nsukka, Nigeria (2012) Space Weather, 10 (10), art. no. S10002, Article

38. Ouattara, F., Christian Zoundi, Christine Amory Mazaudier, Rolland Fleury, Patrick Lassudrie Duchesne Determination of TEC by using pseudo range at Koudougou station in Burkina Faso (2012) Journal des Sciences (in French), Vol 11, No1, 12-19 (ADS)

39. Ouattara, F., Zoundi, C., Fleury, R. Comparison between CODG and GP based TEC observations at Koudougou station in Burkina Faso (2012) Indian Journal of Radio and Space Physics, Vol 41, pp 617-623 (ADS)

40. Ouattara, F., Gnabahou, A., Amory-Mazaudier, C. Seasonal, diurnal and solar-cycle variations of electron density at two West Africa equatorial ionization anomaly stations (2012) International Journal of Geophysics., Volume 2012, Article ID 640463 (ADS) doi: 10.1155/2012/640463

41. Nomura, R., Shiokawa, K., Sakaguchi, K., Otsuka, Y., Connors, M. Polarization of Pc1/EMIC waves and related proton auroras observed at subauroral latitudes (2012) Journal of Geophysical Research A: Space Physics, 117 (2), art. no. A02318, Cited 1 time. Article

42. Nigussie, M., Radicella, S.M., Damtie, B., Nava, B., Yizengaw, E., Ciraolo, L. TEC ingestion into NeQuick 2 to model the East African equatorial ionosphere (2012) Radio Science, Volume 47, Issue 5, CiteID RS5002 (ADS) doi: 10.1029/2012RS004981

43. Norman, Robert J., Dyson, Peter L., Yizengaw, Endawoke, Le Marshall, 
John, Wang, Chuan-Sheng, Carter, Brett A., Wen, Debao, Zhang, Kefei Radio Occultation Measurements From the Australian Microsatellite FedSat (2012) IEEE Transactions on Geoscience and Remote Sensing, vol. 50, issue 11, pp. 4832-4839 (ADS) doi: 10.1109/TGRS.2012.2194295

44. Ngwira, Chigomezyo M., McKinnell, Lee-Anne, Cilliers, Pierre J., Yizengaw, Endawoke An investigation of ionospheric disturbances over South Africa during the magnetic storm on 15 May 2005 (2012) Advances in Space Research, Volume 49, Issue 2, p. 327-335. (ADS) doi: 10.1016/j.asr.2011.09.035

45. Munakata, Kazuoki Probing the heliosphere with the directional anisotropy of galactic cosmic-ray intensity (2012) Comparative Magnetic Minima: Characterizing quiet times in the Sun and Stars, Proceedings of the International Astronomical Union, IAU Symposium, Volume 286, p. 185-194 (ADS) doi: $10.1017 /$ S1743921312004826

46. Maurya, A.K., Veenadhari, B., Singh, R., Kumar, S., Cohen, M.B., Selvakumaran, R., Gokani, S., Pant, P., Singh, A.K., Inan, U.S. Nighttime D region electron density measurements from ELF-VLF tweek radio atmospherics recorded at low latitudes (2012) Journal of Geophysical Research A: Space Physics, 117 (11), art. no. A11308, Article

47. Maurya, A.K., Singh, R., Veenadhari, B., Kumar, S., Cohen, M.B., Selvakumaran, R., Pant, P., Singh, A.K., Siingh, D., Inan, U.S. Morphological features of tweeks and nighttime $\mathrm{D}$ region ionosphere at tweek reflection height from the observations in the low-latitude Indian sector (2012) Journal of Geophysical Research A: Space Physics, 117 (5), art. no. A05301, Cited 1 time. Article

48. K.Shiokawa, Y.Otsuka, S.Oyama, S.Nozawa, M.Satoh, Y.Katoh, Y.Hamaguchi, Y.Yamamoto, J.Meriwether Development of low-cost sky-scanning Fabry-Perot interferometers for airglow and auroral studies (2012) Earth Planets Space, Vol. 64, No. 11, pp. 1033-1046 (ADS) doi: 10.5047/eps.2012.05.004

49. Karapetyan, G.G. Theoretical investigation of thunderstorm induced enhancements of cosmic ray fluxes (2012) Astroparticle Physics, 38 (1), pp. 46-52. Article

50. Koustov, A.V., Hosokawa, K., Nishitani, N., Shiokawa, K., Liu, H. Signatures of moving polar cap arcs in the F-region PolarDARN echoes (2012) Annales Geophysicae, 30 (3), pp. 441-455. Article

51. Hamidi, Z.S., Abidin, Z.Z., Ibrahim, Z.A., Shariff, N.N.M. Indication of radio frequency interference (RFI) sources for solar burst monitoring in Malaysia (2012) INTERNATIONAL CONFERENCE ON PHYSICS AND ITS APPLICATIONS: (ICPAP 2011). AIP Conference Proceedings, Volume 1454, pp. 43-46 (2012). (ADS) doi: 10.1063/1.4730684

52. Haldoupis, C., Cohen, M., Cotts, B., Arnone, E., Inan, U. Long-lasting D-region ionospheric modifications, caused by intense lightning in association with elve and sprite pairs (2012) Geophysical Research Letters, 39 (16), art. no. L16801, Article

53. Fukushima, D., Shiokawa, K., Otsuka, Y., Ogawa, T. Observation of 
equatorial nighttime medium-scale traveling ionospheric disturbances in 630-nm airglow images over 7 years (2012) Journal of Geophysical Research A: Space Physics, 117 (10), art. no. A10324, Article

54. Dahlgren, H., Semeter, J.L., Hosokawa, K., Nicolls, M.J., Butler, T.W., Johnsen, M.G., Shiokawa, K., Heinselman, C. Direct three-dimensional imaging of polar ionospheric structures with the Resolute Bay Incoherent Scatter Radar (2012) Geophysical Research Letters, 39 (5), art. no. L05104,Cited 1 time. Article 55. Dahlgren, H., Perry, G.W., Semeter, J.L., St.-Maurice, J.-P., Hosokawa, K., Nicolls, M.J., Greffen, M., Shiokawa, K., Heinselman, C. Space-time variability of polar cap patches: Direct evidence for internal plasma structuring (2012) Journal of Geophysical Research A: Space Physics, 117 (9), art. no. A09312, Article

56. D'Ujanga, F.M., Mubiru, J., Twinamasiko, B.F., Basalirwa, C., Ssenyonga, T.J. Total electron content variations in equatorial anomaly region (2012) Advances in Space Research, 50 (4), pp. 441-449. Article

57. Chapagain, Narayan P., Makela, Jonathan J., Meriwether, John W., Fisher, Daniel J., Buriti, Ricardo A., Medeiros, Amauri F. Comparison of nighttime zonal neutral winds and equatorial plasma bubble drift velocities over Brazil (2012) Journal of Geophysical Research, Volume 117, Issue A6, CiteID A06309 (ADS) doi: 10.1029/2012JA017620

58. Chilingarian, A., Mkrtchyan, H. Role of the Lower Positive Charge Region (LPCR) in initiation of the Thunderstorm Ground Enhancements (TGEs) (2012) Physical Review D-Particles, Fields, Gravitation and Cosmology, 86 (7), art. no. 072003,Cited 1 time. Article

59. Chilingarian, A., Mailyan, B., Vanyan, L. Recovering of the energy spectra of electrons and gamma rays coming from the thunderclouds (2012) Atmospheric Research, 114-115, pp. 1-16. Cited 3 times. Article

60. Cohen, M.B., Marshall, R.A. ELF/VLF recordings during the $11 \mathrm{March}$ 2011 Japanese Tohoku earthquake (2012) Geophysical Research Letters, vol. 39, issue 11, p. L11804 (2012) (ADS) doi: 10.1029/2012GL052123

61. Chilingarian, A., Bostanjyan, N., Vanyan, L. Neutron bursts associated with thunderstorms (2012) Physical Review D - Particles, Fields, Gravitation and Cosmology, 85 (8), art. no. 085017,Cited 1 time. Article

62. Chilingarian, A., Bostanjyan, N., Karapetyan, T., Vanyan, L. Remarks on recent results on neutron production during thunderstorms (2012) Physical Review D-Particles, Fields, Gravitation and Cosmology, 86 (9), art. no. 093017, Article

63. Chilingarian, Ashot Status of Space Environmental Viewing and Analysis Network (SEVAN) (2012) 39th COSPAR Scientific Assembly. Held 14-22 July 2012, in Mysore, India. Abstract F4.7-4-12, p.333 (ADS)

64. Burke, W.J., Gentile, L.C., Shomo, S.R., Roddy, P.A., Pfaff, R.F. Images of bottomside irregularities observed at topside altitudes (2012) Journal of Geophysical Research A: Space Physics, 117 (3), art. no. A03332, Article

65. Bolaji, O.S., Rabiu, A.B., Oyeyemi, E.O., Yumoto, K. Climatology of the 
inter-hemispheric field-aligned currents system over the Nigeria ionosphere (2012) Journal of Atmospheric and Solar-Terrestrial Physics, 89, pp. 144-153. Article in Press

66. Amory-Mazaudier, C. the International Research Group in geophysics, Europa Africa: a laboratory without borders in the Earth Science and Environment (2012) Journal of Life Sciences vol.6 p 335- 341. (ADS)

67. Akala, Andrew, Yizengaw, Endawoke, Somoye, Emmanuel, Seemala, Gopi The Response of African Equatorial GPS-TEC to Major Geomagnetic Storms during the Ascending Phase (2011) of Solar Cycle 24 (2012) 39th COSPAR Scientific Assembly. Held 14-22 July 2012, in Mysore, India. Abstract E2.2-4-12, p.31 (ADS)

68. Adewale, A.O., Oyeyemi, E.O., Olwendo, J. Solar activity dependence of total electron content derived from GPS observations over Mbarara (2012) Advances in Space Research, 50 (4), pp. 415-426. Article

69. Adewale, A.O., Oyeyemi, E.O., Cilliers, P.J., McKinnell, L.A., Adeloye, A.B. Low solar activity variability and IRI 2007 predictability of equatorial Africa GPS TEC (2012) Advances in Space Research, 49 (2), pp. 316-326. Cited 2 times. Article

70. Adewale, A.O., Oyeyemi, E.O., Adeloye, A.B., Mitchell, C.N., Rose, J.A.R., Cilliers, P.J. A study of L-band scintillations and total electron content at an equatorial station, Lagos, Nigeria (2012) Radio Science, 47 (2), art. no. RS2011, Article

2011

71. Zhang, X.-F., Du, R.-Y., Gu, S.-M., Wu, T., Wang, Y.-N. Anomalous Variation of VLF Signals in the Total Solar Eclipse of 22nd July 2009 (2011) Chinese Astronomy and Astrophysics, 35 (1), pp. 54-61. Cited 1 time. Article

72. Yumoto, K. Update on MAGDAS activities around the globe during ISWI (2011) 2011 IEEE International Conference on Space Science and Communication: "Towards Exploring the Equatorial Phenomena", IconSpace 2011 Proceedings, art. no. 6015894, pp. 254-257. Conference Paper

73. Yumoto, K. Capacity Building of MAGDAS (2011) Sun and Geosphere, vol.6, no.2, p.81-83. (ADS)

74. Yizengaw, E., Zesta, E., Moldwin, M., Damtie, B., Mebrahtu, A., Anad, F., Pfaff, R.F. Observations of ULF wave related equatorial electrojet and density fluctuations (2011) American Geophysical Union, Fall Meeting 2011, abstract \#SA13C-06 (ADS)

75. Yizengaw, E., Moldwin, M.B., Mebrahtu, A., Damtie, B., Zesta, E., Valladares, C.E., Doherty, P. Comparison of storm time equatorial ionospheric electrodynamics in the African and American sectors (2011) Journal of Atmospheric and Solar-Terrestrial Physics, Volume 73, Issue 1, p. 156-163. (ADS) doi: 10.1016/j.jastp.2010.08.008

76. Yumoto, K., Hayakawa, H., Obara, T., Watari, S., Stpp Sub-Committee Of Japan Update on Japan's Contribution to the ISW (2011) Sun and Geosphere, 
vol.6, no.2, p.73-80. (ADS)

77. Reuveni, Y., Price, C., Yair, Y., Yaniv, R. The connection between meteor showers and VLF atmospheric noise signals (2011) Journal of Atmospheric Electricity, Vol. 31, No. 1, p.23-36 (ADS)

78. Uozumi, T., Yumoto, K., Tokunaga, T., Solovyev, S.I., Shevtsov, B.M., Marshall, R., Liou, K., Ohtani, S., Abe, S., Ikeda, A., Kitamura, K., Yoshikawa, A., Kawano, H., Itonaga, M. AKR modulation and global Pi2 oscillation (2011) Journal of Geophysical Research A: Space Physics, 116 (6), art. no. A06214,Cited 1 time. Article

79. Terrazas-Ramos, R. A solar station in Ica - Mutsumi Ishitsuka: A research center to improve education at the university and schools (2011) Proceedings of the International Astronomical Union, 7 (S286), pp. 454-456. Conference Paper

80. Takahashi, H., Onohara, A., Shiokawa, K., Vargas, F., Gobbi, D. Atmospheric wave induced $\mathrm{O} 2$ and $\mathrm{OH}$ airglow intensity variations: Effect of vertical wavelength and damping (2011) Annales Geophysicae, 29 (4), pp. 631-637. Cited 2 times. Article

81. Singh, R., Veenadhari, B., Maurya, A.K., Cohen, M.B., Kumar, S., Selvakumaran, R., Pant, P., Singh, A.K., Inan, U.S. D-region ionosphere response to the total solar eclipse of 22 July 2009 deduced from ELF-VLF tweek observations in the Indian sector (2011) Journal of Geophysical Research A: Space Physics, 116 (10), art. no. A10301, Cited 5 times. Article

82. Samanes, J., Raulin, J.-P. Characteristics of nighttime West-to-East VLF waves propagation using the South America VLF Network (SAVNET) (2011) SBMO/IEEE MTT-S International Microwave and Optoelectronics Conference Proceedings, art. no. 6169250, pp. 598-600. Conference Paper

83. Sibanda, P., Moldwin, M., Zou, S., Yizengaw, E.K. COSMIC TEC tomographic vertical density reconstructions of the topside ionosphere and plasmasphere: Differences between the American and African sectors (2011) American Geophysical Union, Fall Meeting 2011, abstract \#SA32A-04 (ADS)

84. Slosiar, R., Hudec, R., Kocka, M., Marko, R., Zatko, M. Indirect detections and analyses of GRBs by ionospheric response: Toward a SID-monitor network (2011) AIP Conference Proceedings, 1358, pp. 393-396. Conference Paper

85. Rockenbach, M., Dal Lago, A., Gonzalez, W.D., Munakata, K., Kato, C., Kuwabara, T., Bieber, J., Schuch, N.J., Duldig, M.L., Humble, J.E., Al Jassar, H.K., Sharma, M.M., Sabbah, I. Geomagnetic storm's precursors observed from 2001 to 2007 with the Global Muon Detector Network (GMDN) (2011) Geophysical Research Letters, 38 (16), art. no. L16108, Article doi: 10.1029/2011GL048556

86. Raulin, J.-P., Bertoni, F.C.P., Kaufmann, P., Gavila'n, H.R., Correia, E., Hadano, R., Schuch, N.J. Solar-terrestrial, ionospheric and natural phenomena studies using the South America VLF network (SAVNET) (2011) Journal of Atmospheric and Solar-Terrestrial Physics, 73 (11-12), pp. 1581-1586. Article 
87. Rabiu, A.B., Yumoto, K., Falayi, E.O., Bello, O.R., Magdas/Cpmn Group Ionosphere over Africa: Results from Geomagnetic Field Measurements During International Heliophysical Year IHY (2011) Sun and Geosphere, vol.6, no.2, p.63-66 (ADS)

88. Price, C., Yair, Y., Mugnai, A., Lagouvardos, K., Llasat, M.C., Michaelides, S., Dayan, U., Dietrich, S., Galanti, E., Garrote, L., Harats, N., Katsanos, D., Kohn, M., Kotroni, V., Llasat-Botija, M., Lynn, B., Mediero, L., Morin, E., Nicolaides, K., Rozalis, S., Savvidou, K., Ziv, B. The FLASH Project: Using lightning data to better understand and predict flash floods (2011) Environmental Science and Policy, 14 (7), pp. 898-911. Cited 2 times. Article

89. Pham Thi Thu, H., Amory-Mazaudier, C., Le Huy, M. Time variations of the ionosphere at the northern tropical crest of ionization at Phu Thuy, Viet Nam (2011) Annales Geophysicae, Volume 29, Issue 1, 2011, pp.197-207 (ADS) doi: 10.5194/angeo-29-197-2011

90. Pham Thi Thu, H., Amory-Mazaudier, C., Le Huy, M. Sq field characteristics at Phu Thuy, Viet Nam, during solar cycle 23: comparisons with Sq field in other longitude sectors (2011) Annales Geophysicae, Volume 29, Issue 1, 2011, pp.1-17 (ADS) doi: 10.5194/angeo-29-1-2011

91. Ouattara, F., R.Fleury Variability of the CODG TEC and IRI 2001 total electron content (TEC) during IHY campaign period (21 march to 16 April 2008) at Niamey under different geomagnetic activity conditions (2011) Scientific Research and Essays, Vol 6 (17), pp 3609-3622, 26 (ADS)

92. Ouattara, F., Jean-Louis Zerbo Ouagadougou station F2 layer parameters, yearly and seasonal variations during severe geomagnetic storms generated by coronal mass ejections (CME) and fluctuating wind streams (2011) International Journal of the Physical Sciences, Vol 6 (20), pp 4854-4860 (ADS)

93. Nakano, Yoshitake Performance of the SciCR as a component muon detector of the Global Muon Detector Network (GMDN) (2011) Proceedings of the 32nd International Cosmic Ray Conference (ICRC2011), held 11-18 August, 2011 in Beijing, China. Vol. 11 SH3-SH4: Solar and Heliospheric Phenomena, p.260 (ADS)

94. Munakata, K. Probing the heliosphere with the directional anisotropy of galactic cosmic-ray intensity (2011) Proceedings of the International Astronomical Union, 7 (S286), pp. 185-194. Conference Paper

95. Maeda, G., Yumoto, K., Rabiu, A., Ikeda, A., Abe, S., Magdas Group Results of MAGDAS activities at "UN/Nigeria Workshop on ISWI" (Abuja) and of "MAGDAS School” (Lagos) (2011) American Geophysical Union, Fall Meeting 2011, abstract \#ED11A-0750 (ADS)

96. de Mendonc,a, R.R.S., Raulin, J.-P., Bertoni, F.C.P., Echer, E., Makhmutov, V.S., Ferna'ndez, G. STUDY in multiple time scales of intensity cosmic ray measure the surface land [Estudo em mu'ltiplas escalas temporais da intensidade de raios co'smicos medida na superfi'cie terrestre] (2011) Revista Brasileira de Geofisica, 29 (4), pp. 677-690. Article 
97. Mavromichalaki, H., Papaioannou, A., Plainaki, C., Sarlanis, C., Souvatzoglou, G., Gerontidou, M., Papailiou, M., Eroshenko, E., Belov, A., Yanke, V., Flueckiger, E.O., Buetikofer, R., Parisi, M., Storini, M., Klein, K.-L., Fuller, N., Steigies, C.T., Rother, O.M., Heber, B., Wimmer-Schweingruber, R.F., Kudela, K., Strharsky, I., Langer, R., Usoskin, I., Ibragimov, A., Chilingaryan, A., Hovsepyan, G., Reymers, A., Yeghikyan, A., Kryakunova, O., Dryn, E., Nikolayevskiy, N., Dorman, L., Pustil'Nik, L. Applications and usage of the real-time Neutron Monitor Database (2011) Advances in Space Research, Volume 47, Issue 12, p. 2210-2222. (ADS) doi: 10.1016/j.asr.2010.02.019

98. Mene, N.M., Kobea, A.T., Obrou, O.K., Zaka, K.Z., Boka, K., Amory-Mazaudier, C., Assamoi, P. Statistical study of the DP2 enhancement at the dayside dip-equator compared to low latitudes (2011) Annales Geophysicae, Volume 29, Issue 12, 2011, pp.2225-2233 (ADS) doi: 10.5194/angeo-29-2225-2011

99. Meriwether, J.W., Makela, J.J., Huang, Y., Fisher, D.J., Buriti, R.A., Medeiros, A.F., Takahashi, H. Climatology of the nighttime equatorial thermospheric winds and temperatures over Brazil near solar minimum (2011) Journal of Geophysical Research, Volume 116, Issue A4, CiteID A04322 (ADS) doi: 10.1029/2011JA016477

100. Lynn, K.J.W., Otsuka, Y., Shiokawa, K. Simultaneous observations at Darwin of equatorial bubbles by ionosonde-based range/time displays and airglow imaging (2011) Geophysical Research Letters, 38 (23), art. no. L23101,Cited 1 time. Article

101. Kozai, Masayoshi Average spatial density gradient of galactic cosmic rays and its temporal variation observed with the Global Muon Detector Network (GMDN) (2011) Proceedings of the 32nd International Cosmic Ray Conference (ICRC2011), held 11-18 August, 2011 in Beijing, China. Vol. 11 SH3-SH4: Solar and Heliospheric Phenomena, p.300 (ADS)

102. Kuwabara, T., Bieber, J.W., Evenson, P.A., Munakata, K., Kato, C., Tokumaru, M., Duldig, M.L., Humble, J.E., Schuch, N., Rago, A.D., Silva, M.R. Determination of ICME orientations at Earth from galactic cosmic ray observation (2011) American Geophysical Union, Fall Meeting 2011, abstract \#SH24A-03 (ADS)

103. Jansen, Frank, Behrens, Joerg Cosmic Rays for Heliospheric Space Weather Storm Prediction (2011) Cosmic Rays for Particle and Astroparticle Physics. Edited by S Giani (CERN, Switzerland), C Leroy (University of Montreal, Canada), \& P G Rancoita (INFN Milano-Bicocca, Italy). Published by World Scientific Publishing Co. Pte. Ltd., 2011. ISBN \#9789814329033, pp. 378-387 (ADS) doi: 10.1142/9789814329033_0048

104. Hamidi, Z.S., Abidin, Z.Z., Ibrahim, Z.A., Shariff, N.N.M. Indication of Radio Frequency Interference (RFI) sources for solar burst monitoring in Malaysia (2011) AIP Conference Proceedings, 1454 (1), pp. 43-46. Article

105. Hayakawa, M., Raulin, J.P., Kasahara, Y., Bertoni, F.C.P., Hobara, Y., Guevara-Day, W. Ionospheric perturbations in possible association with the 2010 
Haiti earthquake, as based on medium-distance subionospheric VLF propagation data (2011) Natural Hazards and Earth System Science, 11 (2), pp. 513-518. Cited 2 times. Article

106. Hosokawa, K., Moen, J.I., Shiokawa, K., Otsuka, Y. Decay of polar cap patch (2011) Journal of Geophysical Research A: Space Physics, 116 (5), art. no. A05306, Cited 1 time. Article

107. Hosokawa, K., Moen, J.I., Shiokawa, K., Otsuka, Y. Motion of polar cap arcs (2011) Journal of Geophysical Research A: Space Physics, 116 (1), art. no. A01305, Cited 5 times. Article

108. Hovhannisyan, A., Chilingarian, A. Median filtering algorithms for multichannel detectors (2011) Advances in Space Research, Volume 47, Issue 9, p. 1544-1557. (ADS) doi: 10.1016/j.asr.2011.01.007

109. $\tilde{\mathrm{A}}-\mathrm{zg} \tilde{\mathrm{A}} 1 \frac{1}{4} \tilde{\mathrm{A}} \S$, A., Georgieva, K., Yumoto, K. Editorial Appreciation (2011) Sun and Geosphere, vol.6, no.2, p.88. (ADS)

110. Ghamry, E., Mahrous, A., Yasin, N., Fathy, A., Yumoto, K. First Investigation of Geomagnetic Micropulsation, Pi 2, in Egypt (2011) Sun and Geosphere, vol.6, no.2, p.84-87. (ADS)

111. Golkowski, M., Kubicki, M., Cohen, M., Kuak, A., Inan, U.S. Estimation of global lightning activity and observations of atmospheric electric field (2011) Acta Geophysica, 59 (1), pp. 183-204. Cited 3 times. Article

112. Gadimova, S., Haubold, H.J., Danov, D., Georgieva, K., Maeda, G., Yumoto, K., Davila, J.M., Gopalswamy, N. United Nations Basic Space Science Initiative: 2010 Status Report on the International Space Weather Initiative (2011) Sun and Geosphere, vol.6, no.1, p.7-16. (ADS)

113. Davila, Joseph M., Gopalswamy, Nat, Thompson, Barbara J., Bogdan, Tom, Hapgood, Mike The International Space Weather Initiative (ISWI) (2011) The Sun, the Solar Wind, and the Heliosphere, by M.P. Miralles and J. Sanchez Almeida. Proceedings of the conference held 23-30 August, 2009 in Sopron, Hungary. IAGA Special Sopron Book Series, Vol. 4. Berlin: Springer, 2011. ISBN: 978-90-481-9786-6, p.375 (ADS)

114. Correia, E. Study of Antarctic-South America connectivity from ionospheric radio soundings (2011) Oecologia Australis, 15 (1), pp. 32-39. Cited 1 time. Article

115. Chapagain, N.P., Makela, J.J., Meriwether, J.W., Buriti, R.A., Medeiros, A. Comparison of Nighttime Zonal Neutral Winds and Plasma Bubble Drift Velocities over Brazil (2011) American Geophysical Union, Fall Meeting 2011, abstract \#SA22A-04 (ADS)

116. Chilingarian, A., Karapetyan, T. Calculation of the barometric coefficients at the start of the 24th solar activity cycle for particle detectors of Aragats Space Environmental Center (2011) Advances in Space Research, 47 (7), pp. 1140-1146. Cited 2 times. Article doi: 10.1016/j.asr.2010.12.001

117. Correia, E., Kaufmann, P., Raulin, J.-P., Bertoni, F., Gavilan, H.R. Analysis of daytime ionosphere behavior between 2004 and 2008 in Antarctica (2011) 
Journal of Atmospheric and Solar-Terrestrial Physics, 73 (16), pp. 2272-2278. Cited 2 times. Article

118. Chilingarian, A., Hovsepyan, G., Hovhannisyan, A. Particle bursts from thunderclouds: Natural particle accelerators above our heads (2011) Physical Review D-Particles, Fields, Gravitation and Cosmology, 83 (6), art. no. 062001, Cited 7 times. Article

119. Chilingarian, Ashot, Mailyan, Bagrat High Energy Phenomena in the Low Atmosphere; Particle Fluxes from Thunderstorm Clouds (2011) Cosmic Rays for Particle and Astroparticle Physics. Edited by S Giani (CERN, Switzerland), C Leroy (University of Montreal, Canada), \& P G Rancoita (INFN Milano-Bicocca, Italy). Published by World Scientific Publishing Co. Pte. Ltd., 2011. ISBN \#9789814329033, pp. 403-411 (ADS) doi: 10.1142/9789814329033_0051

120. Bolaji, O.S., Rabiu, A.B., Adimula, I.A., Adeniyi, J.O., Yumoto, K. Inter-hemispheric trans-equatorial field-aligned currents deduced from MAGDAS at equatorial zone (2011) Space Research Journal, 4 (1), pp. 12-22. Article

121. Bertoni, F.C.P., Sahai, Y., Raulin, J.-P., Fagundes, P.R., Pillat, V.G., Gimenez de Castro, C.G., Lima, W.L.C. Equatorial spread-F occurrence observed at two near equatorial stations in the Brazilian sector and its occurrence modulated by planetary waves (2011) Journal of Atmospheric and Solar-Terrestrial Physics, 73 (4), pp. 457-463. Cited 2 times. Article

122. Adachi, T., Otsuka, Y., Yamaoka, M., Yamamoto, M., Shiokawa, K., Chen, A.B., Hsu, R.-R. First satellite-imaging observation of medium-scale traveling ionospheric disturbances by FORMOSAT-2/ISUAL (2011) Geophysical Research Letters, 38 (4), art. no. L04101, Cited 1 time. Article

123. Ackah, J.B., Obrou, O.K., Zaka, Z., Mene, M.N., Groves, K. Study of Equatorial Ionospheric Scintillation and TEC characteristics at Solar minimum using GPS-SCINDA data (2011) Sun and Geosphere, vol.6, no.1, p.27-30. (ADS)

124. Ackah, J.-B., Obrou, O.K., Groves, K. Study of the ionospheric scintillation and TEC characteristics at solar minimum in a West African equatorial region using Global Positioning System (GPS) data (2011) 2011 30th URSI General Assembly and Scientific Symposium, URSIGASS 2011, art. no. 6050958, Conference Paper

125. Anderson, D.N., Yizengaw, E. Magnetometer-inferred, Equatorial, Daytime Vertical ExB Drift Velocities Observed in the African Longitude Sector (2011) American Geophysical Union, Fall Meeting 2011, abstract \#SA51D-1982 (ADS)

126. Adewale, A.O., Oyeyemi, E.O., Adeloye, A.B., Ngwira, C.M., Athieno, R. Responses of equatorial $\mathrm{F}$ region to different geomagnetic storms observed by GPS in the African sector (2011) Journal of Geophysical Research A: Space Physics, 116 (12), art. no. A12319, Cited 1 time. Article

2010

127. Zaka, K.Z., Kobea, A.T., Doumbia, V., Richmond, A.D., Maute, A., Mene, N.M., Obrou, O.K., Assamoi, P., Boka, K., Adohi, J.-P., Amory-Mazaudier, C. 
Correction to simulation of electric field and current during the 11 June 1993 disturbance dynamo event: Comparison with the observations (2010) Journal of Geophysical Research, Volume 115, Issue A12, CiteID A12314 (ADS) doi: 10.1029/2010JA016292

128. Zaka, K.Z., Kobea, A.T., Doumbia, V., Richmond, A.D., Maute, A., Mene, N.M., Obrou, O.K., Assamoi, P., Boka, K., Adohi, J.-P., Amory-Mazaudier, C. Simulation of electric field and current during the 11 June 1993 disturbance dynamo event: Comparison with the observations (2010) Journal of Geophysical Research A: Space Physics, 115 (11), art. no. A11307, Cited 2 times. Article 129. Yizengaw, E., Zesta, E., Moldwin, M., Valladares, C.E., Damtie, B., Mebrahtu, A., Biouele, C.M., Yumoto, K., Pfaff, R.F., Heelis, R.A. The Longitudinal Variation of Equatorial Electrodynamics Observations (2010) American Geophysical Union, Fall Meeting 2010, abstract \#SA43C-09 (ADS)

130. Yumoto, K., Takla, E., Ishitsuka, J., Rosales, D., Dutra, S.L., Liu, J.G., Kakinami, Y., Uozumi, T., Abe, S. Study of Geomagnetic Anomalies Related to Earthquakes at Pisco Peru $2007(\mathrm{M}=8.0)$ and at Taiwan 2009 (M=6.4) (Invited) (2010) American Geophysical Union, Fall Meeting 2010, abstract \#NH24A-01 (ADS)

131. Yumoto, Kiyohumi MAGDAS Project at SERC for Space Weather (2010) 38th COSPAR Scientific Assembly. Held 18-15 July 2010, in Bremen, Germany, p.2 (ADS)

132. Yizengaw, Endawoke Equatorial ionospheric electrodynamics observations in the African sector using recently deployed magnetometer and GPS networks (2010) 38th COSPAR Scientific Assembly. Held 18-15 July 2010, in Bremen, Germany, p.2 (ADS)

133. Yizengaw, Endawoke, Moldwin, Mark, Sahai, Yogeshwar, de Jesus, Rodolfo Quiet time Strong equatorial ionospheric anomaly observations during post midnight sector (2010) 38th COSPAR Scientific Assembly. Held 18-15 July 2010, in Bremen, Germany, p.5 (ADS)

134. Wani, M.R., Iqbal, N., Sasmal, S. Studies of VLF radio waves for sudden ionospheric disturbances (SID) in Kashmir region (2010) AIP Conference Proceedings, 1286, pp. 211-213. Conference Paper

135. Webb, David F., Gibson, Sarah E., Thompson, Barbara J. Whole Heliosphere Interval: Overview of JD16 (2010) Highlights of Astronomy, Volume 15, p. 471-479 (ADS) doi: 10.1017/S174392131001032X

136. Tanaka, Y.T., Raulin, J.-P., Bertoni, F.C.P., Fagundes, P.R., Chau, J., Schuch, N.J., Hayakawa, M., Hobara, Y., Terasawa, T., Takahashi, T. First very low frequency detection of short repeated bursts from magnetar SGR J1550-5418 (2010) Astrophysical Journal Letters, 721 (1 PART 2), pp. L24-L27. Cited 3 times. Article

137. Toloman, D., Magdas, D.A., Bratu, I., Giurgiu, L.M., Ardelean, I. Infrared spectra of calcium phosphate glasses (2010) International Journal of Modern Physics B, 24 (3), pp. 351-358. Article 
138. Singh, R., Veenadhari, B., Cohen, M.B., Pant, P., Singh, A.K., Maurya, A.K., Vohat, P., Inan, U.S. Initial results from AWESOME VLF receivers: Set up in low latitude Indian regions under IHY2007/UNBSSI program (2010) Current Science, 98 (3), pp. 398-405. Cited 9 times. Article

139. Sabbah, I., Tokumaru, M., Duldig, M.L., Schuch, N.J. First observed coronal mass ejection from the Middle East using cosmic rays (2010) Kuwait Journal of Science and Engineering, 37 (2 A), pp. 43-61. Article

140. Suzuki, Shin, Nakamura, Takuji, Ejiri, Mitsumu K., Tsutsumi, Masaki, Shiokawa, Kazuo, Kawahara, Takuya D. Simultaneous airglow, lidar, and radar measurements of mesospheric gravity waves over Japan (2010) 38th COSPAR Scientific Assembly. Held 18-15 July 2010, in Bremen, Germany, p.7 (ADS)

141. Stoeva, Penka, Stoev, Alexey Education in astronomy and solar-terrestrial relations in science research environment (2010) 38th COSPAR Scientific Assembly. Held 18-15 July 2010, in Bremen, Germany, p.3 (ADS)

142. Sterner, N.L., Zesta, E., Boudouridis, A., Moldwin, M., Yizengaw, E., Chi, P.J. The South American Meridional B-field Array (SAMBA) and Pc4-5 Wave Studies (2010) American Geophysical Union, Fall Meeting 2010, abstract \#SM11B-1752 (ADS)

143. Schuch, N.J., Munakata, K., Bieber, J.W., Duldig, M.L., Sabbah, I. The global muon detector network - GMDN and space weather prediction (2010) 61st International Astronautical Congress 2010, IAC 2010, 12, pp. 9968-9972. Conference Paper

144. Schuch, Nelson Jorge, Munakata, Kazuoki, Dal Lago, Alisson, Marcos Denardini, Clezio, Echer, Ezequiel, Demtrio Gonzalez Alarcon, Walter, da Silva, Marlos, Rigozo, Nivaor R., Petry, Adriano, Kirsch Pinheiro, Damaris, Braga, Carlos Roberto, Vinicius Dias Silveira, Marcos, Ronan Coelho Stekel, Tardelli, Espindola Antunes, Cassio, Ramos Vieira, Lucas, Kemmerich, Nikolas, Kato, Chihiro, Fushishita, Akira, Fujii, Zenjirou, Bieber, John W., Evenson, Paul, Kuwabara, Takao, Duldig, Marcus L., Humble, John E., Chilingarian, Ashot, Sabbah, Ismail, Jansen, Frank The Global Muon Detector Network-GMDN and the space situational awareness (2010) 38th COSPAR Scientific Assembly. Held 18-15 July 2010, in Bremen, Germany, p.28 (ADS)

145. Suzuki, S., Nakamura, T., Ejiri, M.K., Tsutsumi, M., Shiokawa, K., Kawahara, T.D. Simultaneous airglow, lidar, and radar measurements of mesospheric gravity waves over Japan (2010) Journal of Geophysical Research D: Atmospheres, 115 (24), art. no. D24113, Cited 1 time. Article

146. da Silva, Marlos, Dal Lago, Alisson, Demitrio Gonzalez Alarcon, Walter, Munakata, Kazuoki, Fushishita, Akira, Kuwabara, Takao, Bieber, John W., Schuch, Nelson Jorge, Duldig, Marcus L., Humble, John E., Sabbah, Ismail Global muon detector network observing geomagnetic storm's precursor since march 2001 (2010) 38th COSPAR Scientific Assembly. Held 18-15 July 2010, in Bremen, Germany, p.12 (ADS)

147. Shiokawa, K., Mori, M., Fukushima, D., Otsuka, Y., Oyama, S., Nozawa, 
S., Connors, M.G. Gravity waves and instabilities in the ionosphere imaged by the Optical Mesosphere Thermosphere Imagers (OMTIs) (2010) American Geophysical Union, Fall Meeting 2010, abstract \#SA31A-1714 (ADS)

148. Sterner, Lt.Nathan, Zesta, Eftyhia, Boudouridis, Athanasios, Moldwin, Mark, Yizengaw, Endawoke, Chi, Peter The South American Meridional B-field Array (SAMBA) and Pc4-5 Wave Studies (2010) 38th COSPAR Scientific Assembly. Held 18-15 July 2010, in Bremen, Germany, p.7 (ADS)

149. Shiokawa, Kazuo, Otsuka, Yuichi Ground network observations of the thermosphere and the mesosphere by the Optical Mesosphere Thermosphere Imagers (OMTIs) (2010) 38th COSPAR Scientific Assembly. Held 18-15 July 2010, in Bremen, Germany, p.3 (ADS)

150. Reuveni, Yuval, Price, Colin, Greenberg, Eran, Shuval, Abraham Natural atmospheric noise statistics from VLF measurements in the eastern Mediterranean (2010) Radio Science, Volume 45, Issue 5, CiteID RS5015 (ADS) doi: 10.1029/2009RS004336

151. Rabiu, A., Yumoto, K., Bello, O. Spatial and Temporal Variations of Solar Quiet Daily Sq Variation and Equatorial Electrojet Over Africa: Results From International Heliophysical Year (2010) American Geophysical Union, Fall Meeting 2010, abstract \#SA51D-1652 (ADS)

152. Roddy, P.A., Hunton, D.E., Ballenthin, J.O., Groves, K.M. Correlation of in situ measurements of plasma irregularities with ground-based scintillation observations (2010) Journal of Geophysical Research A: Space Physics, 115 (6), art. no. A06303, Cited 5 times. Article

153. Reuveni, Y., Price, C., Greenberg, E., Shuval, A. Natural atmospheric noise statistics from VLF measurements in the eastern Mediterranean (2010) Radio Science, 45 (5), art. no. RS5015, Cited 1 time. Article

154. Raulin, Jean-Pierre, Davila, Joseph M., Bogdan, Thomas, Yumoto, Kiyohumi, Leibacher, John The Future of IHY Campaigns: Transition to the International Space Weather Initiative (2010) Highlights of Astronomy, Volume 15, p. 501-503 (ADS) doi: 10.1017/S1743921310010392

155. Raulin, J.-P., Bertoni, F.C.P., Gavila'n, H.R., Samanes, J.C. Long-term and transient forcing of the low ionosphere monitored by SAVNET (2010) AIP Conference Proceedings, 1286, pp. 103-125. Conference Paper

156. Raulin, Jean-Pierre, Bertoni, Fernando C.P., Gavila'n, Hernan R., Guevara-Day, Walter, Rodriguez, Rodolfo, Fernandez, Germa'n, Correia, Emilia, Kaufmann, Pierre, Pacini, Alessandra, Stekel, Tardelli R.C., Lima, Washington L.C., Schuch, Nelson J., Fagundes, Paulo R., Hadano, Rubens Solar flare detection sensitivity using the South America VLF Network (SAVNET) (2010) Journal of Geophysical Research, Volume 115, Issue A7, CiteID A07301 (ADS) doi: 10.1029/2009JA015154

157. Rabiu, Babatunde Variability of Ionosphere over Africa: Results from International Heliophysical Year IHY (2010) 38th COSPAR Scientific Assembly. Held 18-15 July 2010, in Bremen, Germany, p.2 (ADS) 
158. RoÅ $\AA^{a}$, D., Angelov, Ch., Arakelyan, K., Arsov, T., Avakyan, K., Chilingarian, A., Chilingaryan, S., Hovhanissyan, A., Hovhannisyan, T., Hovsepyan, G., Sargsyan, D., HrÅ3/4ina, D., Kalapov, I., Karapetyan, T., Kozliner, L., Mailyan, B., Maria, D., Nishev, A., Pokhsraryan, D., Reymers, A., Romtajn, I., Stamenov, J., Tchorbadjieff, A., Vanyan, L. SEVAN CRO Particle Detector for Solar Physics and Space Weather research (2010) Central European Astrophysical Bulletin, Vol. 34, p. 115-122 (ADS)

159. Oyama, S., Shiokawa, K., Suzuki, S., Nozawa, S., Otsuka, Y., Tsutsumi, M., Hall, C.M., Meek, C., Manson, A.H. Propagation direction of the nighttime mesospheric gravity waves in the $\mathrm{OH}$ airglow images at Tromsoe, Norway in winter 2009 (2010) American Geophysical Union, Fall Meeting 2010, abstract \#SA31A-1704 (ADS)

160. Oyama, Shin-Ichiro, Shiokawa, Kazuo, Nozawa, Satonori, Otsuka, Yuichi, Tsutsumi, Masaki, Suzuki, Shin, Hall, Chris, Meek, Chris, Manson, Alan Propagation characteristics of nighttime mesospheric waves observed with an all-sky camera at Tromsoe, Norway in 2009-2010 (2010) 38th COSPAR Scientific Assembly. Held 18-15 July 2010, in Bremen, Germany, p.10 (ADS)

161. Oyama, S., Shiokawa, K., Kurihara, J., Tsuda, T.T., Nozawa, S., Ogawa, Y., Otsuka, Y., Watkins, B.J. Lower-thermospheric wind fluctuations measured with an FPI during pulsating aurora at Troms?, Norway (2010) Annales Geophysicae, 28 (10), pp. 1847-1857. Cited 3 times. Article

162. NaitAmor, S., AlAbdoadaim, M.A., Cohen, M.B., Cotts, B.R.T., Soula, S., Chanrion, O., Neubert, T., Abdelatif, T. VLF observations of ionospheric disturbances in association with TLEs from the EuroSprite-2007 campaign (2010) Journal of Geophysical Research, Volume 115, Issue 1, CiteID A00E47 (ADS) doi: 10.1029/2009JA015026

163. Maeda, G., Yumoto, K., Kakinami, Y., Tokunaga, T., Fujimoto, A., Ikeda, A., Yamazaki, Y., Abe, S., Sakai, M., Eto, N., Shinohara, M., Magdas Project Team Current Status of MAGDAS Deployment in Africa (2010) American Geophysical Union, Fall Meeting 2010, abstract \#SA51D-1650 (ADS)

164. Moldwin, M., Sibanda, P., Zou, S., Yizengaw, E. Understanding the dynamic ionospheric signature of the plasmapause (Invited) (2010) American Geophysical Union, Fall Meeting 2010, abstract \#SA34A-03 (ADS)

165. M.Tokumaru, M.Kojima, K.Fujiki, K.Munakata, T.Kuwabara, K.Marubashi Relation between loop-shaped interplanetary disturbances and the magnetic flux rope (2010) Advances in Geosciences, 21, pp. 21-32 (ADS) doi: 10.1142/9789812838209_0002

166. Makela, Jonathan J., Meriwether, John W., Buriti, Ricardo, Hedlund, Peter Coordinated Observations of Neutral Winds, Scintillation Drift Velocities and Equatorial Plasma Bubbles (2010) 38th COSPAR Scientific Assembly. Held 18-15 July 2010, in Bremen, Germany, p.5 (ADS)

167. Mahrous, A., Ghamry, E., Elhawary, R., Fathy, I., Yamazaki, Y., Abe, S., Uozumi, T., Yumoto, K. First MAGDAS installation at Fayum in Egypt (2010) 
Advances in Space Research, 46 (5), pp. 613-617. Article

168. Mailyan, B., Chilingarian, A. Investigation of diurnal variations of cosmic ray fluxes measured with using ASEC and NMDB monitors (2010) Advances in Space Research, 45 (11), pp. 1380-1387. Cited 4 times. Article

169. Mailyan, Bagrat, Chilingarian, Ashot Investigation of diurnal variations of cosmic ray fluxes measured with using ASEC and NMDB monitors (2010) Advances in Space Research, Volume 45, Issue 11, p. 1380-1387. (ADS) doi: 10.1016/j.asr.2010.01.027

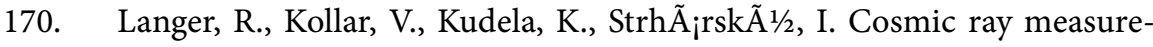
ments at lomnick $\tilde{A} 1 \frac{1}{2}$ peak: Possibilities of developments in CCS (2010) Contributions of the Astronomical Observatory Skalnate Pleso, 40 (3), pp. 159-164. Article

171. Lefeuvre, Francois, Mc Kinnel, Lee-Anne, Chukwuma, Victor, Amory-Mazaudier, Christine Radio Science in Africa (2010) EGU General Assembly 2010, held 2-7 May, 2010 in Vienna, Austria, p.6382 (ADS)

172. Lago, A.Dal, Guarnieri, F.L., da Silva, M.R., Gonzalez, W.D., Braga, C.R., Schuch, N.J., Munakata, K., Kato, C., Bieber, J.W., Kuwabara, T., Tokumaru, M., Duldig, M.L., Humble, J.E. On Cosmic Rays, IP Structures and Geospace Consequences During WHI (2010) Highlights of Astronomy, Volume 15, p. 488-490 (ADS) doi: 10.1017/S1743921310010355

173. Kucera, Therese A., Gibson, S.E., Rastawicki, D., Dove, J., de Toma, G., Hao, J., Hudson, H.S., Marque, C., McIntosh, P.S., Reeves, K.K., Schmidt, D.J., Sterling, A.C., Tripathi, D.K., Williams, D.R., Zhang, M. Geometric Model of a Coronal Cavity (2010) Bulletin of the American Astronomical Society, Vol. 41, p.890 (ADS)

174. Kemmerich, Nikolas, Dal Lago, Alisson, Schuch, Nelson Jorge, da Silva, Marlos, Ramos Vieira, Lucas, Braga, Carlos Roberto, Vinicius Dias Silveira, Marcos, Ronan Coelho Stekel, Tardelli Anisotropy Observed at the Brazilian Southern Space Observatory by the Multidirectional Muon Detector -MMD (2010) 38th COSPAR Scientific Assembly. Held 18-15 July 2010, in Bremen, Germany, p.9 (ADS)

175. Karapetyan, G.G. Investigation of cosmic ray anisotropy based on Tsumeb neutron monitor data (2010) Astroparticle Physics, 33 (3), pp. 146-150. Cited 1 time. Article

176. Hosokawa, K., Tsugawa, T., Shiokawa, K., Otsuka, Y., Nishitani, N., Ogawa, T., Hairston, M.R. Dynamic temporal evolution of polar cap tongue of ionization during magnetic storm (2010) Journal of Geophysical Research A: Space Physics, 115 (12), art. no. A12333, Cited 3 times. Article

177. Hudec, R., Sloiar, R. Indirect detections and analyses of GRBs by ionospheric response (2010) AIP Conference Proceedings, 1248, pp. 59-60. Conference Paper

178. Hosokawa, K., St-Maurice, J.-P., Sofko, G.J., Shiokawa, K., Otsuka, Y., Ogawa, T. Reorganization of polar cap patches through shears in the background 
plasma convection (2010) Journal of Geophysical Research A: Space Physics, 115 (1), art. no. A01303, Cited 5 times. Article

179. Hamid, N.S.A., Gopir, G., Ismail, M., Misran, N., Usang, M.D., Yumoto, K. Scaling and fractal properties of the horizontal geomagnetic field at the tropical stations of Langkawi and Davao in February 2007 (2010) AIP Conference Proceedings, 1250, pp. 516-519. Conference Paper

180. Huang, Y., Makela, J.J., Meriwether, J.W., Buriti, R.A. A Cloud Detection Algorithm Based Upon FPI Measurements (2010) American Geophysical Union, Fall Meeting 2010, abstract \#SA11B-1587 (ADS)

181. Haubold, H.J., Gadimova, S. Status Report on the United Nations Basic Space Science Initiative (UNBSSI) (2010) eprint arXiv:1002.1413 (ADS)

182. Haubold, H.J., Gadimova, S. Progress in basic space science education and research: The UNBSSI (2010) Space Policy, 26 (1), pp. 61-63. Cited 2 times. Article

183. Haubold, H.J., Gadimova, S., Balogh, W. Contributions of the United Nations Office for Outer Space Affairs to the International Space Weather Initiative (ISWI) (2010) eprint arXiv:1011.5663 (ADS)

184. Haubold, H.J., Gadimova, S., Balogh, W. Contributions of the United Nations Office for Outer Space Affairs to the International Space Weather Initiative (ISWI) (2010) 61st International Astronautical Congress 2010, IAC 2010, 5, pp. 3859-3866. Conference Paper

185. Gadimova, Sharafat, Haubold, Hans Monitoring Solar-terrestrial Interaction at the United Nations Office at Vienna (2010) 38th COSPAR Scientific Assembly. Held 18-15 July 2010, in Bremen, Germany, p.3 (ADS)

186. Grams, Guilherme, Schuch, Nelson Jorge, Braga, Carlos Roberto, Purushottam Kane, Rajaram, Echer, Ezequiel, Ronan Coelho Stekel, Tardelli Statistical study of muons counts rates in different directions, observed at the Brazilian Southern Space Observatory (2010) 38th COSPAR Scientific Assembly. Held 18-15 July 2010, in Bremen, Germany, p.7 (ADS)

187. Gopalswamy, N., Davila, J.M. International Space Weather Initiative (ISWI) (2010) Proceedings of the 20th National Solar Physics Meeting, held 31 May - 4 June, 2010 in Papradno, Slovakia, p. 160 (ADS)

188. Fushishita, A., Kuwabara, T., Kato, C., Yasue, S., Bieber, J.W., Evenson, P., Da Silva, M.R., Dal Lago, A., Schuch, N.J., Tokumaru, M., Duldig, M.L., Humble, J.E., Sabbah, I., Jassar, H.K.Al, Sharma, M.M., Munakata, K. Precursors of the Forbush Decrease on 2006 December 14 Observed with the Global Muon Detector Network (GMDN) (2010) The Astrophysical Journal, Volume 715, Issue 2, pp. 1239-1247 (2010). (ADS) doi: 10.1088/0004-637X/715/2/1239

189. Fushishita, A., Kuwabara, T., Kato, C., Yasue, S., Bieber, J.W., Evenson, P., Da Silva, M.R., Lago, A.D., Schuch, N.J., Tokumaru, M., Duldig, M.L., Humble, J.E., Sabbah, I., Al Jassar, H.K., Sharma, M.M., Munakata, K. Precursors of the Forbush decrease on 2006 December 14 observed with the Global Muon Detector Network (GMDN) (2010) Astrophysical Journal Letters, 715 (2), pp. 
1239-1247. Cited 5 times. Article

190. DorotoviÄ], I. ISWI in Slovakia. (Slovak Title: ISWI na Slovensku) (2010) Proceedings of the 20th National Solar Physics Meeting, held 31 May - 4 June, 2010 in Papradno, Slovakia, p. 161 (ADS)

191. Donnarumma, I., Vercellone, S., Grube, J., Raiteri, C.M., Villata, M., VERITAS Collaboration, GASP-WEBT Team, MAGIC Collaboration The June 2008 Flare of Markarian 421 from Optical to TeV Energies (2010) Accretion and Ejection in AGN: a Global View. Proceedings of a conference held June 22-26, 2009 in Como, Italy. Edited by Laura Maraschi, Gabriele Ghisellini, Roberto Della Ceca, and Fabrizio Tavecchio., p.295 (ADS)

192. Damtie, B., Negussie, M., Radichella, S., Nava, B., Yizengaw, E., Groves, K.M. Electrodynamics and temporal characteristics of the East African ionosphere inferred from ground-based observations (Invited) (2010) American Geophysical Union, Fall Meeting 2010, abstract \#SA43C-02 (ADS)

193. Davila, Joseph, Gopalswamy, Nat The International Space Weather Initiative (2010) 38th COSPAR Scientific Assembly. Held 18-15 July 2010, in Bremen, Germany, p.3 (ADS)

194. Davila, J.M., Gopalswamy, N., Haubold, H. Opportunities for Ionospheric Science as Part of the International Space Weather Initiative (ISWI) (Invited) (2010) American Geophysical Union, Fall Meeting 2010, abstract \#SA43C-01 (ADS)

195. Corbett, Ian Highlights of Astronomy, Vol. 15 (2010) Highlights of Astronomy, Vol. 15, by Edited by Ian Corbett, Cambridge, UK: Cambridge University Press, 2010 (ADS)

196. Cohen, M.B., Inan, U.S., Said, R.K., Briggs, M.S., Fishman, G.J., Connaughton, V., Cummer, S.A. A lightning discharge producing a beam of relativistic electrons into space (2010) Geophysical Research Letters, Volume 37, Issue 18, CiteID L18806 (ADS) doi: 10.1029/2010GL044481

197. Cohen, M.B., Inan, U.S., Paschal, E.W. Sensitive broadband ELF/VLF radio reception with the AWESOME instrument (2010) IEEE Transactions on Geoscience and Remote Sensing, 48 (1), art. no. 5272358, pp. 3-17. Cited 32 times. Article

198. Chilingarian, A., Daryan, A., Arakelyan, K., Hovhannisyan, A., Mailyan, B., Melkumyan, L., Hovsepyan, G., Chilingaryan, S., Reymers, A., Vanyan, L. Ground-based observations of thunderstorm-correlated fluxes of high-energy electrons, gamma rays, and neutrons (2010) Physical Review D, vol. 82, Issue 4, id. 043009 (ADS) doi: 10.1103/PhysRevD.82.043009

199. Chilingarian, A., Daryan, A., Arakelyan, K., Hovhannisyan, A., Mailyan, B., Melkumyan, L., Hovsepyan, G., Chilingaryan, S., Reymers, A., Vanyan, L. Ground-based observations of thunderstorm-correlated fluxes of high-energy electrons, gamma rays, and neutrons (2010) Physical Review D - Particles, Fields, Gravitation and Cosmology, 82 (4), art. no. 043009,Cited 12 times. Article 200. Carrano, C.S., Valladares, C.E., Semala, G.K., Bridgwood, C.T., Adeniyi, 
J., Amaeshi, L.L., Damtie, B., D'Ujanga Mutonyi, F., Ndeda, J.D., Baki, P., Obrou, O.K., Okere, B., Tsidu, G.M. GPS Observations of Plasma Bubbles and Scintillations over Equatorial Africa (2010) American Geophysical Union, Fall Meeting 2010, abstract \#SA43C-06 (ADS)

201. Chilingarian, A., Bostanjyan, N. On the relation of the Forbush decreases detected by ASEC monitors during the 23rd solar activity cycle with ICME parameters (2010) Advances in Space Research, Volume 45, Issue 5, p. 614-621. (ADS) doi: 10.1016/j.asr.2009.09.001

202. Chilingarian, Ashot Space Environmental Viewing and Analysis Network (SEVAN) (2010) 38th COSPAR Scientific Assembly. Held 18-15 July 2010, in Bremen, Germany, p.2 (ADS)

203. Bisi, M.M., Jackson, B.V., Hick, P.P., Clover, J.M., Hamilton, S., Tokumaru, M., Fujiki, K. Large-Scale Heliospheric Structure during Solar-Minimum Conditions using a 3D Time-Dependent Reconstruction Solar-Wind Model and STELab IPS Observations (2010) TWELFTH INTERNATIONAL SOLAR WIND CONFERENCE. AIP Conference Proceedings, Volume 1216, pp. 355-358 (2010). (ADS) doi: 10.1063/1.3395873

204. Bisi, M.M., Jackson, B.V., Hick, P.P., Clover, J.M., Hamilton, S., Tokumaru, M., Fujiki, K. Large-scale heliospheric structure during solar-minimum conditions using a 3D time-dependent reconstruction solar-wind model and STELab IPS observations (2010) AIP Conference Proceedings, 1216, pp. 355-358. Conference Paper

205. Bisi, Mario M., Jackson, B.V., Clover, J.M., Hick, P.P., Buffington, A., Tokumaru, M. A Summary of 3-D Reconstructions of the Whole Heliosphere Interval and Comparison with in-Ecliptic Solar Wind Measurements from STEREO, ACE, and Wind Instrumentation (2010) Highlights of Astronomy, Volume 15, p. 480-483 (ADS) doi: 10.1017/S1743921310010331

206. Bertoni, F.C.P., Raulin, J.-P., Gavilan, H.R., Kaufmann, P., Raymundo, T.E. Periodic and quiescent solar activity effects in the low ionosphere, using SAVNET data (2010) AIP Conference Proceedings, 1286, pp. 177-187. Conference Paper

207. Bertoni, Fernando C.P, Raulin, Jean-Pierre, Gavilan, Hernan R., Guevara-Day, Walter R., Rogrigues R., Fernandez G. SAVNET: A ground-based facility for studying ionospheric, atmospheric and natural phenomena (2010) Radio Science Bulletin, 334, 43-48, 2010 (ADS)

208. Babayev, E.S. Space weather awesome VLF monitoring in Azerbaijani site and international cooperation (2010) 61st International Astronautical Congress 2010, IAC 2010, 5, pp. 3853-3858. Conference Paper

209. Braga, Carlos Roberto, Dal Lago, Alisson, Schuch, Nelson Jorge, da Silva, Marlos, Echer, Ezequiel, Demitrio Gonzalez Alarcon, Walter, Munakata, Kazuoki, Kuwabara, Takao, Kato, Chihiro, Bieber, John W. Cosmic ray modulation by interplanetary disturbances (2010) 38th COSPAR Scientific Assembly. Held 18-15 July 2010, in Bremen, Germany, p.11 (ADS) 
210. Basu, S., Basu, S., MacKenzie, E., Bridgwood, C., Valladares, C.E., Groves, K.M., Carrano, C. Specification of the occurrence of equatorial ionospheric scintillations during the main phase of large magnetic storms within solar cycle 23 (2010) Radio Science, 45 (5), art. no. RS5009, Cited 4 times. Article

211. Fushishita, A., Narumi, T., Kato, C., Yasue, S., Munakata, K., Okazaki, Y., Kuwabara, T., Bieber, J.W., Evenson, P., Da Silva, M.R., Dal Lago, A., Schuch, N.J., Tokumaru, M., Duldig, M.L., Humble, J.E., Sabbah, I., Kota, J. Drift effects and the average features of cosmic ray density gradient in CIRs during successive two solar minimum periods (2010) Advances in Geosciences, 21, 199-210 (ADS) doi: 10.1142/9789812838209_0016

212. Adewale, A.O., Oyeyemi, E.O., Ofuase, U.D. Comparison between observed ionospheric foF2 and IRI-2001 predictions over periods of severe geomagnetic activities at Grahamstown, South Africa (2010) Advances in Space Research, 45 (3), pp. 368-373. Cited 2 times. Article

2009

213. IHY posters (2009) Earth, Moon, and Planets, Volume 104, Issue 1-4, pp. 161-165 (ADS) doi: 10.1007/s11038-008-9279-2

214. Zaka, K.Z., Kobea, A.T., Assamoi, P., Obrou, O.K., Doumbia, V., Boka, K., Adohi, J.-P., Mene, N.M. Latitudinal profiles of the ionospheric disturbance dynamo magnetic signature: comparison with the DP2 magnetic disturbance (2009) Ann. Geophys., 27, No.9, pp. 3523-3536 (ADS)

215. Zazyan, M., Chilingarian, A. Calculations of the sensitivity of the particle detectors of ASEC and SEVAN networks to galactic and solar cosmic rays (2009) Astroparticle Physics, 32 (3-4), pp. 185-192. Cited 2 times. Article doi: 10.1016/j.astropartphys.2009.08.001

216. Yumoto, K. International heliophysical year activities in Japan (2009) Data Science Journal, 8, pp. S14-S23. Article

217. Yumoto, K. MAGDAS project for space weather research and application (2009) AIP Conference Proceedings, 1144, pp. 173-178. Cited 2 times. Conference Paper

218. Yumoto, K., Yamazaki, Y., Abe, S., Uozumi, T. EEJ and Sq Variations Observed at MAGDAS/CPMN Stations (2009) American Geophysical Union, Fall Meeting 2009, abstract \#SA23B-1472 (ADS)

219. Yizengaw, E., Moldwin, M.B. African meridian b-field education and research (amber) array (2009) Earth, Moon and Planets, 104 (1-4), pp. 237-246. Cited 1 time. Conference Paper doi: 10.1007/s11038-008-9287-2

220. Yizengaw, E., Moldwin, M., Mebrahtu, A., Damtie, B., Pfaff, R.F., Zesta, E., Valladares, C.E. Equatorial ionospheric electrodynamics observations in the African and American longitudinal sectors (2009) American Geophysical Union, Fall Meeting 2009, abstract \#SA14A-06 (ADS)

221. Yumoto, Kiyohumi MAGDAS Project for Space Weather Research and Application (2009) FUTURE PERSPECTIVES OF SPACE PLASMA AND PARTICLE INSTRUMENTATION AND INTERNATIONAL COLLABORATIONS: 
Proceedings of the International Conference. AIP Conference Proceedings, Volume 1144, pp. 173-178 (2009). (ADS) doi: 10.1063/1.3169284

222. Yumoto, K., Ikemoto, S., Cardinal, M.G., Hayakawa, M., Hattori, K., Liu, J.Y., Saroso, S., Ruhimat, M., Husni, M., Widarto, D., Ramos, E., McNamara, D., Otadoy, R.E., Yumul, G., Ebora, R., Servando, N. A new ULF wave analysis for Seismo-Electromagnetics using CPMN/MAGDAS data (2009) Physics and Chemistry of the Earth, 34 (6-7), pp. 360-366. Cited 3 times. Article

223. Yumoto, K., Group, M. MAGDAS Project for Space Weather during IHY/ISWI (2009) American Geophysical Union, Spring Meeting 2009, abstract \#SM12A-01 (ADS)

224. Yizengaw, Endawoke, Moldwin, Mark B., Sahai, Yogeshwar, de Jesus, Rodolfo Strong post midnight equatorial ionospheric anomaly observations during magnetically quiet periods (2009) Journal of Geophysical Research, Volume 114, Issue A12, CiteID A12308 (ADS) doi: 10.1029/2009JA014603

225. Watari, Shinichi, Boteler, David Delivery of Space Weather Information in Collaboration with the International Space Environment Service (ISES) (2009) Earth, Moon, and Planets, Volume 104, Issue 1-4, pp. 287-293 (ADS) doi: $10.1007 /$ s1 1038-008-9285-4

226. Webb, David F. Division II / IAU Representative Report International Heliophysical Year (2009) Transactions IAU, Volume 4, Issue 27A, Reports on Astronomy 2006-2009. Edited by Karel van der Hucht. Cambridge: Cambridge University Press, 2009, p. 145-147 (ADS) doi: 10.1017/S1743921308025386

227. Watari, S., Boteler, D. Delivery of space weather information in collaboration with the International Space Environment Service (ISES) (2009) Earth, Moon and Planets, 104 (1-4), pp. 287-293. Cited 2 times. Conference Paper

228. Ueno, S., Shibata, K., Kitai, R., Ichimoto, K., Nagata, S., Isobe, H., Kimura, G., Nakatani, Y., Kadota, M., Komori, H., Ishii, T.T., Morita, S., Otsuji, K. The CHAIN-project and installation of flare monitoring telescopes in developing countries (2009) Data Science Journal, 8, pp. S51-S58. Article

229. Uozumi, T., Abe, S., Kitamura, K., Tokunaga, T., Yoshikawa, A., Kawano, H., Marshall, R., Morris, R.J., Shevtsov, B.M., Solovyev, S.I., McNamara, D.J., Liou, K., Ohtani, S., Itonaga, M., Yumoto, K. Propagation characteristics of Pi 2 pulsations observed at high- And low-latitude MAGDAS/CPMN stations: A statistical study (2009) Journal of Geophysical Research A: Space Physics, 114 (11), art. no. A11207, Cited 2 times. Article

230. Tsuruda, Yoshihiro, Fujimoto, Akiko, Kurahara, Naomi, Hanada, Toshiya, Yumoto, Kiyohumi, Cho, Mengu QSAT: The Satellite for Polar Plasma Observation (2009) Earth, Moon, and Planets, Volume 104, Issue 1-4, pp. 349-360 (ADS) doi: 10.1007/s11038-008-9281-8

231. Tulunay, Y., Tulunay, E., Kocabas, Z., Altuntas, E., Yapici, T., Senalp, E.T., Hippler, R. Enhancing the Awareness of the Interaction of the Space Weather and Public: Some Case Studies in Turkey (2009) EGU General Assembly 2009, held 19-24 April, 2009 in Vienna, Austria, p.3662 (ADS) 
232. Tsuruda, Y., Fujimoto, A., Kurahara, N., Hanada, T., Yumoto, K., Cho, M. QSAT: The satellite for polar plasma observation (2009) Earth, Moon and Planets, 104 (1-4), pp. 349-360. Cited 3 times. Conference Paper

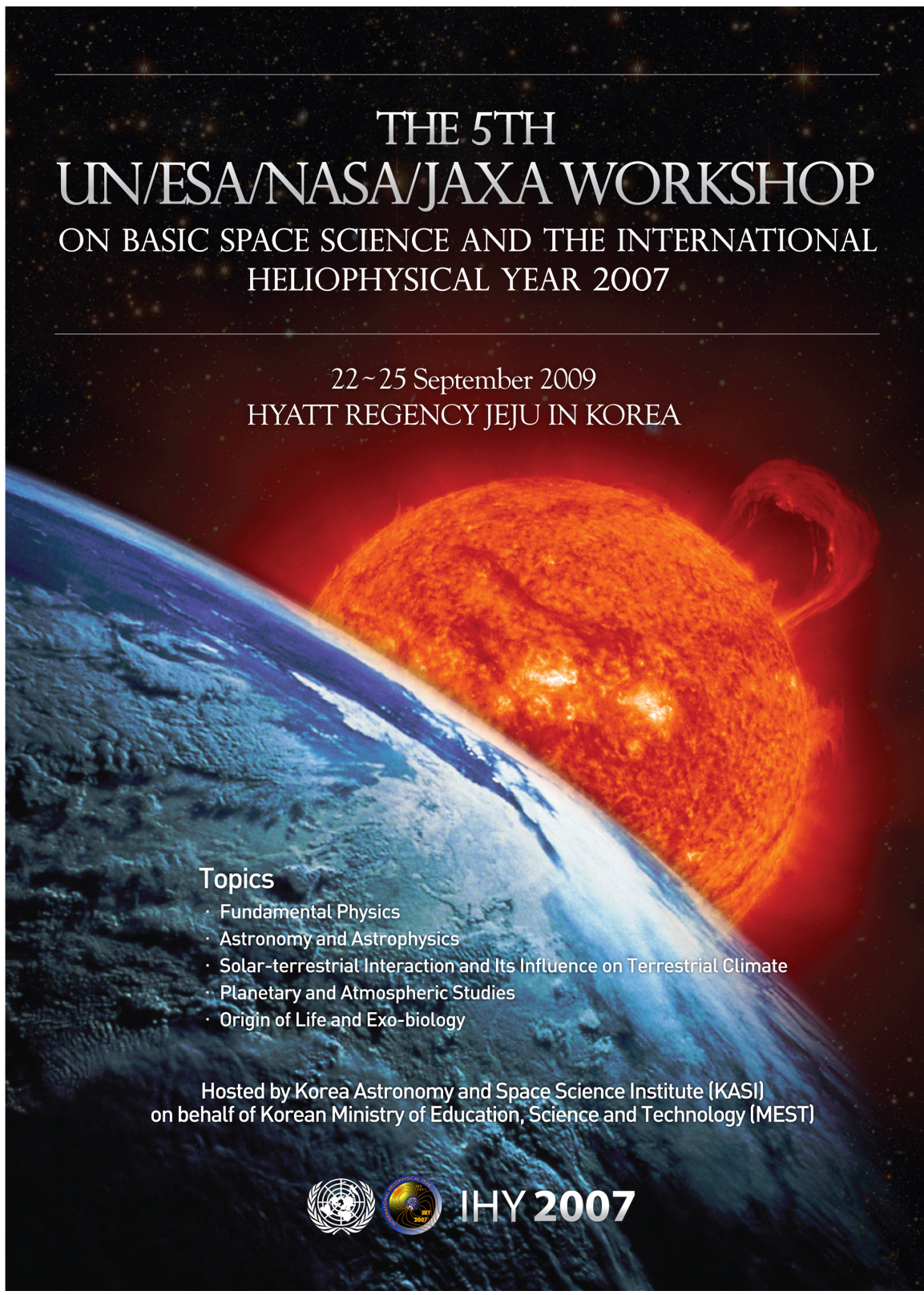

The poster of the 2009 UN/ESA/NASA/JAXA Workshop for the preparation of the International Space Weather Initiative (ISWI) that was scheduled to start in 2010: http://ihy.kasi.re.kr/meeting.php.

233. Thompson, Barbara J., Gopalswamy, Natchimuthuk, Davila, Joseph M., Haubold, Hans J. Putting the "I" in IHY: The United Nations Report for the International Heliophysical Year 2007 (2009) Putting the I in IHY: The United Nations Report for the International Heliophysical Year 2007, edited by Barbara J. Thompson, Natchimuthuk Gopalswamy, Joseph M. Davila and Hans J. Haubold. 
ISBN 978-3-211-99179-4. Published by Springer, Dordrecht, The Netherlands, 2009. (ADS)

234. Shiokawa, K., Otsuka, Y., Ogawa, T. Propagation characteristics of nighttime mesospheric and thermospheric waves observed by optical mesosphere thermosphere imagers at middle and low latitudes (2009) Earth, Planets and Space, Volume 61, p. 479-491. (ADS)

235. Shiokawa, K., Otsuka, Y., Ogawa, T. Propagation characteristics of nighttime mesospheric and thermospheric waves observed by optical mesosphere thermosphere imagers at middle and low latitudes (2009) Earth, Planets and Space, 61 (4), pp. 479-491. Cited 26 times. Conference Paper

236. Slosiar, R., Hudec, R. Indirect detections and analyses of GRBs by ionospheric response (2009) AIP Conference Proceedings, 1133, pp. 428-430. Conference Paper

237. Shiokawa, K., Hosokawa, K., Sakaguchi, K., Ieda, A., Otsuka, Y., Ogawa, T., Connors, M. The optical mesosphere thermosphere imagers (OMTIs) for network measurements of aurora and airglow (2009) AIP Conference Proceedings, 1144, pp. 212-215. Conference Paper

238. Suzuki, S., Hosokawa, K., Otsuka, Y., Shiokawa, K., Ogawa, T., Nishitani, N., Shibata, T.F., Koustov, A.V., Shevtsov, B.M. Coordinated observations of nighttime medium-scale traveling ionospheric disturbances in 630-nm airglow and HF radar echoes at midlatitudes (2009) Journal of Geophysical Research A: Space Physics, 114 (7), art. no. A07312, Cited 3 times. Article

239. Reuveni, Yuval, Price, Colin A new approach for monitoring the 27-day solar rotation using VLF radio signals on the Earth's surface (2009) Journal of Geophysical Research, Volume 114, Issue A10, CiteID A10306 (ADS) doi: 10.1029/2009JA014364

240. Raulin, J.-P., de Matos David, P.C., Hadano, R., Saraiva, A.C.V., Correia, E., Kaufmann, P. The South America VLF NETwork (SAVNET) (2009) Earth, Moon and Planets, 104 (1-4), pp. 247-261. Cited 9 times. Conference Paper

241. Raulin, J.P., Correia de Matos David, P., Hadano, R., Saraiva, A.C.V., Correia, E., Kaufmann, P. The south America VLF NETwork (SAVNET): Development, installation status, first results (2009) Geofisica Internacional, 48 (3), pp. 253-261. Cited 3 times. Article

242. Rabiu, A.B., Adimula, I.A., Yumoto, K., Adeniyi, J.O., Maeda, G. Preliminary results from the magnetic field measurements using Magdas at Ilorin, Nigeria (2009) Earth, Moon and Planets, 104 (1-4), pp. 173-179. Cited 2 times. Conference Paper doi: 10.1007/s11038-008-9290-7

243. Petitdidier, M. Status of the recommendations on the African cyber infrastructure expressed by the scientific community written in 2007 (2009) EGU General Assembly 2009, held 19-24 April, 2009 in Vienna, Austria, p.7349 (ADS) 244. Ouattara F. Relationship between Geomagnetic classes activity phases and their occurrence during sunspot cycle (2009) Annals of Geophysics, Vol. 52, No2, pp. 107-116 (ADS) 
245. Otadoy, R.E.S., McNamara, S.J.D., Yumoto, K. Proposal to use MAGDAS/CPMN to study the equatorial electrojet: A Philippine contribution to the international heliophysical year (2009) Earth, Moon and Planets, 104 (1-4), pp. 167-172. Conference Paper

246. Ogawa, T., Otsuka, Y., Shiokawa, K., Tsugawa, T., Saito, A., Hoshinoo, K., Matunaga, K., Kubota, M., Ishii, M. Medium-scale travelling ionospheric disturbances and plasma bubbles observed by an all-sky airglow imager at yonaguni. Japan (2009) Terrestrial, Atmospheric and Oceanic Sciences, 20 (1), pp. 287-295. Cited 2 times. Article

247. Obrou, O.K., M.N.Mene, A.T.Kobea, K.Z.Zaka Equatorial Total Electron Content (TEC) at low and high solar activity (2009) Advances in Space Research, vol 43, issue 11, pp 1757-1761 (ADS)

248. Ouattara, F., Amory-Mazaudier, C. Solar-geomagnetic activity and Aa indices toward a standard classification (2009) Journal of Atmospheric and Solar-Terrestrial Physics, 71 (17-18), pp. 1736-1748. Cited 3 times. Article

249. Ouattara, F., Amory-Mazaudier, C., Menvielle, M., Simon, P., Legrand, J.-P. On the long term change in the geomagnetic activity during the 20th century (2009) Annales Geophysicae, 27 (5), pp. 2045-2051. Cited 6 times. Article 250. Ouattara, F., Amory-Mazaudier, C., Fleury, R., Lassudrie Duchesne, P., Vila, P., Petitdidier, M. West African equatorial ionospheric parameters climatology based on Ouagadougou ionosonde station data from June 1966 to February 1998 (2009) Annales Geophysicae, Volume 27, Issue 6, 2009, pp.2503-2514 (ADS) doi: 10.5194/angeo-27-2503-2009

251. Maeda, G., Yumoto, K. Progress report on the deployment of MAGDAS (2009) Earth, Moon and Planets, 104 (1-4), pp. 271-276. Cited 3 times. Conference Paper doi: 10.1007/s11038-008-9284-5

252. Maeda, G., Yumoto, K., Abe, S., Uozumi, T. The World's Largest Real Time Magnetometer Array: MAGDAS (2009) American Geophysical Union, Fall Meeting 2009, abstract \#SM11B-1583 (ADS)

253. Messerotti, M., Ritschel, B. The electronic geophysical year (eGY) in Europe: Organization and activities (2009) Earth, Moon and Planets, 104 (1-4), pp. 59-61. Conference Paper doi: 10.1007/s11038-008-9263-x

254. Monstein, Kh.A., Lesovoy, S.V., Maslov, A.I. Observations of the solar radio emission with the Callisto spectrometer (2009) Geomagnetism and Aeronomy, Volume 49, Issue 7, pp.856-859 (ADS) doi: 10.1134/S0016793209070056 255. Makela, J.J., Meriwether, J.W., Lima, J.P., Miller, E.S., Armstrong, S.J. The remote equatorial nighttime observatory of ionospheric regions project and the international heliospherical year (2009) Earth, Moon and Planets, 104 (1-4), pp. 211-226. Cited 5 times. Conference Paper doi: 10.1007/s11038-008-9289-0

256. Messerotti, M., Baccomi, R., Iugovaz, D., Lilensten, J. A terrella device for simulating aurora-like phenomena in a box (2009) Earth, Moon and Planets, 104 (1-4), pp. 55-58. Conference Paper doi: 10.1007/s11038-008-9262-y

257. Meloni, A., Alfonsi, L. Geomagnetism and Aeronomy activities in Italy 
during IGY, 1957/58 (2009) Annals of Geophysics, 52 (2), pp. 127-135. Article 258. Koustov, A., Nishitani, N., Ponomarenko, P.V., Shiokawa, K., Suzuki, S., Shevtsov, B.M., MacDougall, J.W. Joint observations of a travelling ionospheric disturbance with the Paratunka OMTI camera and the Hokkaido HF radar (2009) Annales Geophysicae, 27 (6), pp. 2399-2406. Cited 1 time. Article

259. Kozyra, J.U., Gibson, S.E., de Toma, G., Emery, B.A., Onsager, T.G., Sojka, J.J., Thompson, B.J. All Solar Minima are not Alike: Consequences at Earth (2009) American Geophysical Union, Spring Meeting 2009, abstract \#U12A-04 (ADS) 260. Kuwabara, T., Bieber, J.W., Evenson, P., Munakata, K., Yasue, S., Kato, C., Fushishita, A., Tokumaru, M., Duldig, M.L., Humble, J.E., Silva, M.R., Dal Lago, A., Schuch, N.J. Determination of interplanetary coronal mass ejection geometry and orientation from ground-based observations of galactic cosmic rays (2009) Journal of Geophysical Research A: Space Physics, 114 (5), art. no. A05109, Cited 5 times. Article

261. Ismail-Zadeh, A., Beer, T. Ninety Years of International Cooperation in Geophysics (2009) American Geophysical Union, Spring Meeting 2009, abstract \#U21B-01 (ADS)

262. Hamid, N.S.A., Gopir, G., Ismail, M., Misran, N., Hasbi, A.M., Usang, M.D., Yumoto, K. The Hurst exponents of the geomagnetic horizontal component during quiet and active periods (2009) 2009 International Conference on Space Science and Communication, IconSpace - Proceedings, art. no. 5352642, pp. 186-190. Cited 1 time. Conference Paper

263. Hosokawa, K., Kashimoto, T., Suzuki, S., Shiokawa, K., Otsuka, Y., Ogawa, T. Motion of polar cap patches: A statistical study with all-sky airglow imager at Resolute Bay, Canada (2009) Journal of Geophysical Research, Volume 114, Issue A4, CiteID A04318 (ADS) doi: 10.1029/2008JA014020

264. Hosokawa, K., Kashimoto, T., Suzuki, S., Shiokawa, K., Otsuka, Y., Ogawa, T. Motion of polar cap patches: A statistical study with all-sky airglow imager at Resolute Bay, Canada (2009) Journal of Geophysical Research A: Space Physics, 114 (4), art. no. A04318, Cited 8 times. Article

265. Haubold, H.J., Balogh, W.R. The United Nations Basic Space Science Initiative (UNBSSI) (2009) Advances in Space Research, 43 (12), pp. 1854-1862. Cited 3 times. Article

266. Hidy, G.M., Brook, J.R., Chow, J.C., Green, M., Husar, R.B., Lee, C., Scheffe, R.D., Swanson, A., Watson, J.G. Remote sensing of particulate pollution from space: Have we reached the promised land? (2009) Journal of the Air and Waste Management Association, 59 (10), pp. 1130-1139. Cited 5 times. Review

267. Goncharenko, L. Observations of Thermospheric Winds at Middle Latitude During the Current Solar Minimum (2009) American Geophysical Union, Spring Meeting 2009, abstract \#SA13B-02 (ADS)

268. Garner, T.W., Gaussiran II, T.L., York, J.A., Munton, D.M., Slack III, C.M., Mahrous, A.M. Ionospheric tomography network of Egypt: A new receiver network in support of the international heliophysical year (2009) Earth, Moon and 
Planets, 104 (1-4), pp. 227-235. Cited 3 times. Conference Paper doi: $10.1007 / \mathrm{s} 11038-008-9286-3$

269. Gardini, A., Damiani, A., Storini, M. Minor components of the terrestrial atmosphere during the 2nd campaign of IHY/CIP 57* (2009) EGU General Assembly 2009, held 19-24 April, 2009 in Vienna, Austria, p.11965 (ADS)

270. Fujimoto, A., Ueno, T., Yumoto, K. A science mission for QSAT project: Study of FACs in the polar and equatorial regions (2009) Earth, Moon and Planets, 104 (1-4), pp. 181-187. Cited 1 time. Conference Paper

271. Fucugauchi, J.U., Perez-Cruz, L.L., Alaniz-Alvarez, S. International Year of Planet Earth-Accomplishments, Activities, Challenges and Plans in Mexico (2009) American Geophysical Union, Fall Meeting 2009, abstract \#U11B-0026 (ADS)

272. de Franceschi, Giorgiana, Alfonsi, Lucilla, Altadill, David, Bencze, Pal, Bourdillon, Alain, Buresova, Dalia, Cander, Ljiljana R., de La Morena, Benito, Economou, Lefteris, Herraiz, Miguel, Kauristie, Kirsti, Lastovicka, Jan, Pau, Silvia, Rodriguez, Gracia, Stamper, Richard, Stanislawska, Iwona The contribution to IHY from the COST296 Action MIERS: Mitigation of Ionospheric Effects on Radio Systems (2009) Earth, Moon, and Planets, Volume 104, Issue 1-4, pp. 63-67 (ADS) doi: 10.1007/s11038-008-9275-6

273. Franceschi, G., Alfonsi, L., Altadill, D., Bencze, P., Bourdillon, A., Buresova, D., Cander, L.R., de la Morena, B., Economou, L., Herraiz, M., Kauristie, K., Lastovicka, J., Pau, S., Rodriguez, G., Stamper, R., Stanislawska, I. The contribution to IHY from the COST296 action MIERS: Mitigation of Ionospheric effects on radio systems (2009) Earth, Moon and Planets, 104 (1-4), pp. 63-67. Conference Paper

274. E.Greenberga, C.Pricea, Y.Yairb, C.Haldoupisc, O.Chanriond, T.Neubert ELF/VLF signatures of sprite-producing lightning discharges observed during the 2005 EuroSprite campaign (2009) J. of Atm. and Solar-Terrestrial Physics,Vol.71, Iss.12, pp. 1254-1266 (ADS) doi: 10.1016/j.jastp.2009.05.005

275. Donnarumma I., Vittorini V., Vercellone S., et al. The June 2008 Flare of Markarian 421 From Optical To TeV Energies (2009) Astrophysical Journal Letters 691, No1, L13-L19 (ADS) doi: 10.1088/0004-637X/691/1/L13

276. Donnarumma, I., Vittorini, V., Vercellone, S., del Monte, E., Feroci, M., D'Ammando, F., Pacciani, L., Chen, A.W., Tavani, M., Bulgarelli, A., Giuliani, A., Longo, F., Pucella, G., Argan, A., Barbiellini, G., Boffelli, F., Caraveo, P., Cattaneo, P.W., Cocco, V., Costa, E., DeParis, G., Di Cocco, G., Evangelista, Y., Fiorini, M., Froysland, T., Frutti, M., Fuschino, F., Galli, M., Gianotti, F., Labanti, C., Lapshov, I., Lazzarotto, F., Lipari, P., Marisaldi, M., Mastropietro, M., Mereghetti, S., Morelli, E., Morselli, A., Pellizzoni, A., Perotti, F., Picozza, P., Porrovecchio, G., Prest, M., Rapisarda, M., Rappoldi, A., Rubini, A., Soffitta, P., Trifoglio, M., Trois, A., Vallazza, E., Zambra, A., Zanello, D., Pittori, C., Santolamazza, P., Verrecchia, F., Giommi, P., Colafrancesco, S., Salotti, L., Villata, M., Raiteri, C.M., Chen, W.P., Efimova, N.V., Jordan, B., Konstantinova, T.S., Koptelova, E., Kurtanidze, O.M., 
Larionov, V.M., Ros, J.A., Sadun, A.C., Anderhub, H., Antonelli, L.A., Antoranz, P., Backes, M., Baixeras, C., Balestra, S., Barrio, J.A., Bartko, H., Bastieri, D., Gonza'lez, J.Becerra, Becker, J.K., Bednarek, W., Berger, K., Bernardini, E., Biland, A., Bock, R.K., Bonnoli, G., Bordas, P., Tridon, D.Borla, Bosch-Ramon, V., Bretz, T., Britvitch, I., Camara, M., Carmona, E., Chilingarian, A., Commichau, S., Contreras, J.L., Cortina, J., Costado, M.T., Covino, S., Curtef, V., Dazzi, F., DeAngelis, A., DeCea del Pozo, E., de los Reyes, R., DeLotto, B., DeMaria, M., DeSabata, F., Mendez, C.Delgado, Dominguez, A., Dorner, D., Doro, M., Elsaesser, D., Errando, M., Ferenc, D., Ferna'ndez, E., Firpo, R., Fonseca, M.V., Font, L., Galante, N., Garci'a Lo'pez, R.J., Garczarczyk, M., Gaug, M., Goebel, F., Hadasch, D., Hayashida, M., Herrero, A., Hoehne-Moench, D., Hose, J., Hsu, C.C., Huber, S., Jogler, T., Kranich, D., La Barbera, A., Laille, A., Leonardo, E., Lindfors, E., Lombardi, S., Lo’pez, M., Lorenz, E., Majumdar, P., Maneva, G., Mankuzhiyil, N., Mannheim, K., Maraschi, L., Mariotti, M., Marti'nez, M., Mazin, D., Meucci, M., Meyer, M., Miranda, J.M., Mirzoyan, R., Moldo'n, J., Moles, M., Moralejo, A., Nieto, D., Nilsson, K., Ninkovic, J., Oya, I., Paoletti, R., Paredes, J.M., Pasanen, M., Pascoli, D., Pauss, F., Pegna, R.G., Perez-Torres, M.A., Persic, M., Peruzzo, L., Prada, F., Prandini, E., Puchades, N., Raymers, A., Rhode, W., Ribo', M., Rico, J., Rissi, M., Robert, A., Ru"gamer, S., Saggion, A., Saito, T.Y., Salvati, M., Sanchez-Conde, M., Sartori, P., Satalecka, K., Scalzotto, V., Scapin, V., Schweizer, T., Shayduk, M., Shinozaki, K., Shore, S.N., Sidro, N., Sierpowska-Bartosik, A., Sillanpaa, A., Sitarek, J., Sobczynska, D., Spanier, F., Stamerra, A., Stark, L.S., Takalo, L., Tavecchio, F., Temnikov, P., Tescaro, D., Teshima, M., Tluczykont, M., Torres, D.F., Turini, N., Vankov, H., Venturini, A., Vitale, V., Wagner, R.M., Wittek, W., Zabalza, V., Zandanel, F., Zanin, R., Zapatero, J., Acciari, V., Aliu, E., Arlen, T., Beilicke, M., Benbow, W., Bradbury, S.M., Buckley, J.H., Bugaev, V., Butt, Y., Byrum, K., Cannon, A., Cesarini, A., Chow, Y.C., Ciupik, L., Cogan, P., Colin, P., Cui, W., Daniel, M.K., Dickherber, R., Duke, C., Ergin, T., Fegan, S.J., Finley, J.P., Finnegan, G., Fortin, P., Furniss, A., Gall, D., Gillanders, G.H., Guenette, R., Gyuk, G., Grube, J., Hanna, D., Holder, J., Horan, D., Hui, C.M., Humensky, T.Brian, Imran, A., Kaaret, P., Karlsson, N., Kertzman, M., Kieda, D., Kildea, J., Konopelko, A., Krawczynski, H., Krennrich, F., Lang, M.J., LeBohec, S., Maier, G., McCann, A., McCutcheon, M., Milovanovic, A., Moriarty, P., Nagai, T., Ong, R.A., Otte, A.N., Pandel, D., Perkins, J.S., Pichel, A., Pohl, M., Ragan, K., Reyes, L.C., Reynolds, P.T., Roache, E., Rose, H.J., Schroedter, M., Sembroski, G.H., Smith, A.W., Steele, D., Swordy, S.P., Theiling, M., Toner, J.A., Valcarcel, L., Varlotta, A., Wakely, S.P., Ward, J.E., Weekes, T.C., Weinstein, A., Williams, D.A., Wissel, S., Wood, M., Zitzer, B. The June 2008 Flare of Markarian 421 from Optical to TeV Energies (2009) The Astrophysical Journal Letters, Volume 691, Issue 1, pp. L13-L19 (2009). (ADS) doi: 10.1088/0004-637X/691/1/L13

277. de Wit Dudok, Thierry, Chilingarian, Ashot A., Karapetyan, Grigori G. Techniques for characterizing weak transients in cosmic ray records, as measured by neutron monitor networks (2009) Acta Geophysica, Volume 57, Issue 1, 
pp.102-115 (ADS) doi: 10.2478/s11600-008-0038-6

278. Davila, J.M., Thompson, B.J., Gopalswamy, N. The international heliophysical year (2009) Data Science Journal, 8, pp. S2-S10. Article

279. Chilingarian, A. SEVAN particle-detector network for Solar Physics and Space Weather research (2009) EGU General Assembly 2009, held 19-24 April, 2009 in Vienna, Austria, p.11443 (ADS)

280. C.Amory-Mazaudier, W.Schroder, G.Giovanni Introduction to the special part of normal issue of JASTP “The Time Varying Sun" (2009) Journal of Atmos. and Solar Terr. Phys., 71, iss. 17-18, 1681-1682 (ADS)

281. Chilingaryan, Suren, Chilingarian, Ashot, Danielyan, Varuzhan, Eppler, Wolfgang Advanced data acquisition system for SEVAN (2009) Advances in Space Research, Volume 43, Issue 4, p. 717-720. (ADS)

doi: 10.1016/j.asr.2008.10.008

282. Chilingarian, A., Mirzoyan, R., Zazyan, M. Cosmic Ray research in Armenia (2009) Advances in Space Research, Volume 44, Issue 10, p. 1183-1193. (ADS) doi: 10.1016/j.asr.2008.11.029

283. Chilingarian, A., Hovsepyan, G., Arakelyan, K., Chilingaryan, S., Danielyan, V., Avakyan, K., Yeghikyan, A., Reymers, A., Tserunyan, S. Space environmental viewing and analysis network (SEVAN) (2009) Earth, Moon and Planets, 104 (1-4), pp. 195-210. Cited 5 times. Conference Paper

doi: $10.1007 / \mathrm{s} 11038-008-9288-1$

284. Carrano, C.S., Yizengaw, E., Doherty, P.H., Bridgwood, C.T., Adeniyi, J.O., Amaeshi, L.L., Pedersen, T.R., Groves, K.M., Roddy, P.A., Caton, R.G. Ground- and Space-Based Observations of Ionospheric Irregularities over Nigeria during Solar Minimum (2009) American Geophysical Union, Fall Meeting 2009, abstract \#SA31B-1424 (ADS)

285. Chilingaryan, S., Chilingarian, A., Danielyan, V., Eppler, W. Advanced data acquisition system for SEVAN (2009) Advances in Space Research, 43 (4), pp. 717-720. Cited 2 times. Article

286. Chilingarian, A., Bostanjyan, N. Cosmic ray intensity increases detected by Aragats Space Environmental Center monitors during the 23rd solar activity cycle in correlation with geomagnetic storms (2009) Journal of Geophysical Research, Volume 114, Issue A9, CiteID A09107 (ADS) doi: 10.1029/2009JA014346 287. Chilingarian, Ashot Statistical study of the detection of solar protons of highest energies at 20 January 2005 (2009) Advances in Space Research, Volume 43, Issue 4, p. 702-707. (ADS) doi: 10.1016/j.asr.2008.10.005

288. Bong, Su-Chan, Kim, Yeon-Han, Roh, Heeseon, Cho, Kyung-Suk, Park, Young-Deuk, Choi, Seonghwan, Baek, Ji-Hye, Monstein, Christian, Benz, Arnold O., Moon, Yong-Jae, Kim, Sungsoo S. Constructino of an E-Callisto Station in Korea (2009) Journal of the Korean Astronomical Society, vol. 42, no. 1, pp. 1-7 (ADS)

289. Bisi, Mario, Jackson, B.V., Hick, P.P.L., Clover, J.M., Tokumaru, M., Fujiki, K., Fallows, R.A., Breen, A.R. Three-Dimensional Reconstructions of the Solar 
Wind: During Solar Minimum Conditions (2009) Bulletin of the American Astronomical Society, Vol. 41, p.866 (ADS)

290. Barton, C.E., C.Amory-Mazaudier, B.Barry, V.Chukwuma, R.L.Cottrell, U.Kalim, A.Mebrathu, M.Petitdidier, B.Rabiu, C.Reeves Electronic Geophysical Year: Start of the Art and Results: eGY-Africa: Addressing the digital divide for science in Africa (2009) Russian Journal of Earth Sciences, Vol. 11, ES003 (ADS) 291. Benz, A.O., Monstein, C., Meyer, H., Manoharan, P.K., Ramesh, R., Altyntsev, A., Lara, A., Paez, J., Cho, K.-S. A World-Wide Net of Solar Radio Spectrometers: e-CALLISTO (2009) Earth, Moon, and Planets, Volume 104, Issue 1-4, pp. 277-285 (ADS) doi: 10.1007/s11038-008-9267-6

292. Benz, Arnold O., Monstein, Christian, Beverland, Michael, Meyer, Hansueli, Stuber, Bruno High Spectral Resolution Observation of Decimetric Radio Spikes Emitted by Solar Flares - First Results of the Phoenix-3 Spectrometer (2009) Solar Physics, Volume 260, Issue 2, pp.375-388 (ADS)

doi: 10.1007/s11207-009-9455-1

293. Briand, C., Antonucci, E., Haubold, H.J. Preface to the proceedings of the European general assembly on IHY 2007 (2009) Earth, Moon and Planets, 104 (1-4), pp. 1-2. Editorial doi: 10.1007/s11038-008-9277-4

294. Amory-Mazaudier, C., J.P.Legrand A comment on the paper "Solar activity and its influence on climate" (2009) Netherlands Journal of Geosciences -Geologie En Mijnbouw 88(3), 177-177 (ADS)

295. Amory-Mazaudier, C., Gregori, G., Schroeder, W. Introduction to several papers on special section of The Time Varying Sun (2009) Journal of Atmospheric and Solar-Terrestrial Physics, Volume 71, Issue 17-18, p. 1681-1682. (ADS) doi: 10.1016/j.jastp.2009.10.001

296. Araujo-Pradere, E., Fuller-Rowell, T., Codrescu, M., Husler, M., Coloma, F. Current and Future Real-time Data Requirements for Space Weather Applications (2009) American Geophysical Union, Spring Meeting 2009, abstract \#G22A-02 (ADS)

297. Amory-Mazaudier, C., Basu, S., Bock, O., Combrink, A., Groves, K., Fuller Rowell, T., Lassudrie-Duchesne, P., Petitdidier, M., Yizengaw, E. International heliophysical year: GPS network in Africa (2009) Earth, Moon and Planets, 104 (1-4), pp. 263-270. Cited 1 time. Conference Paper

doi: $10.1007 /$ s11038-008-9273-8

298. Albert J., Aliu E., and 146 co-authors, Periodic very high energy gamma-ray emission from ls $\mathrm{i}+61$ degrees 303 observed with the MAGIC telescope (2009) Astrophysical Journal Letters, V.693,No1, pp.303-310 (ADS)

doi: 10.1088/0004-637X/693/1/303

299. Adewale, A.O., Oyeyemi, E.O., McKinnell, L.A. Comparisons of observed ionospheric F2 peak parameters with IRI-2001 predictions over South Africa (2009) Journal of Atmospheric and Solar-Terrestrial Physics, 71 (2), pp. 273-284. Cited 5 times. Article

300. Aliu, E., Anderhub, H., Antonelli, L.A., Antoranz, P., Backes, M., Baix- 
eras, C., Barrio, J.A., Bartko, H., Bastieri, D., Becker, J.K., Bednarek, W., Berger, K., Bernardini, E., Biland, A., Bock, R.K., Bonnoli, G., Bordas, P., Borla Tridon, D., Bosch-Ramon, V., Bretz, T., Britvitch, I., Camara, M., Carmona, E., Chilingarian, A., Commichau, S., Contreras, J.L., Cortina, J., Costado, M.T., Covino, S., Curtef, V., Dazzi, F., de Angelis, A., de Cea Del Pozo, E., de Los Reyes, R., de Lotto, B., de Maria, M., de Sabata, F., Delgado Mendez, C., Dominguez, A., Dorner, D., Doro, M., Elsaesser, D., Errando, M., Fagiolini, M., Ferenc, D., Ferna'ndez, E., Firpo, R., Fonseca, M.V., Font, L., Galante, N., Garci'a Lo'pez, R.J., Garczarczyk, M., Gaug, M., Goebel, F., Hadasch, D., Hayashida, M., Herrero, A., Ho"hne, D., Hose, J., Hsu, C.C., Huber, S., Jogler, T., Kranich, D., La Barbera, A., Laille, A., Leonardo, E., Lindfors, E., Lombardi, S., Longo, F., Lo'pez, M., Lorenz, E., Majumdar, P., Maneva, G., Mankuzhiyil, N., Mannheim, K., Maraschi, L., Mariotti, M., Marti'nez, M., Mazin, D., Meucci, M., Meyer, M., Miranda, J.M., Mirzoyan, R., Moles, M., Moralejo, A., Nieto, D., Nilsson, K., Ninkovic, J., Otte, N., Oya, I., Paoletti, R., Paredes, J.M., Pasanen, M., Pascoli, D., Pauss, F., Pegna, R.G., Perez-Torres, M.A., Persic, M., Peruzzo, L., Piccioli, A., Prada, F., Prandini, E., Puchades, N., Raymers, A., Rhode, W., Ribo', M., Rico, J., Rissi, M., Robert, A., Ru"gamer, S., Saggion, A., Saito, T.Y., Salvati, M., Sanchez-Conde, M., Sartori, P., Satalecka, K., Scalzotto, V., Scapin, V., Schweizer, T., Shayduk, M., Shinozaki, K., Shore, S.N., Sidro, N., Sierpowska-Bartosik, A., Sillanpaa”, A., Sitarek, J., Sobczynska, D., Spanier, F., Stamerra, A., Stark, L.S., Takalo, L., Tavecchio, F., Temnikov, P., Tescaro, D., Teshima, M., Tluczykont, M., Torres, D.F., Turini, N., Vankov, H., Venturini, A., Vitale, V., Wagner, R.M., Wittek, W., Zabalza, V., Zandanel, F., Zanin, R., Zapatero, J. Improving the performance of the single-dish Cherenkov telescope MAGIC through the use of signal timing (2009) Astroparticle Physics, Volume 30, Issue 6, p. 293-305. (ADS)

doi: 10.1016/j.astropartphys.2008.10.003

301. Aliu, E., Anderhub, H., Antonelli, L.A., Antoranz, P., Backes, M., Baixeras, C., Balestra, S., Barrio, J.A., Bartko, H., Bastieri, D., Becerra Gonzalez, J., Becker, J.K., Bednarek, W., Berger, K., Bernardini, E., Biland, A., Bock, R.K., Bonnoli, G., Bordas, P., Borla Tridon, D., Bosch-Ramon, V., Bretz, T., Britvitch, I., Camara, M., Carmona, E., Chilingarian, A., Commichau, S., Contreras, J.L., Cortina, J., Costado, M.T., Covino, S., Curtef, V., Dazzi, F., DeAngelis, A., DeCea del Pozo, E., de los Reyes, R., DeLotto, B., DeMaria, M., DeSabata, F., Delgado Mendez, C., Dominguez, A., Dorner, D., Doro, M., Elsaesser, D., Errando, M., Ferenc, D., Fernandez, E., Firpo, R., Fonseca, M.V., Font, L., Galante, N., Garcia LÃ ${ }^{3}$ pez, R.J., Garczarczyk, M., Gaug, M., Goebel, F., Hadasch, D., Hayashida, M., Herrero, A., Hoehne-Moench, D., Hose, J., Hsu, C.C., Huber, S., Jogler, T., Kranich, D., La Barbera, A., Laille, A., Leonardo, E., Lindfors, E., Lombardi, S., Longo, F., LÃ pez, M., Lorenz, E., Majumdar, P., Maneva, G., Mankuzhiyil, N., Mannheim, K., Maraschi, L., Mariotti, M., Martinez, M., Mazin, D., Meucci, M., Meyer, M., Miranda, J.M., Mirzoyan, R., Mold $\tilde{A}^{3} n$, J., Moles, M., Moralejo, A., Nieto, D., Nilsson, K., Ninkovic, J., Otte, N., Oya, I., Paoletti, R., Paredes, J.M., Pasanen, M., Pascoli, 
D., Pauss, F., Pegna, R.G., Perez-Torres, M.A., Persic, M., Peruzzo, L., Prada, F., Prandini, E., Puchades, N., Raymers, A., Rhode, W., Rib ̃ ${ }^{3}$, M., Rico, J., Rissi, M., Robert, A., RÃ¹/4gamer, S., Saggion, A., Saito, T.Y., Salvati, M., Sanchez-Conde, M., Sartori, P., Satalecka, K., Scalzotto, V., Scapin, V., Schweizer, T., Shayduk, M., Shinozaki, K., Shore, S.N., Sidro, N., Sierpowska-Bartosik, A., Sillanpaaa, A., Sitarek, J., Sobczynska, D., Spanier, F., Stamerra, A., Stark, L.S., Takalo, L., Tavecchio, F., Temnikov, P., Tescaro, D., Teshima, M., Tluczykont, M., Torres, D.F., Turini, N., Vankov, H., Venturini, A., Vitale, V., Wagner, R.M., Wittek, W., Zabalza, V., Zandanel, F., Zanin, R., Zapatero, J. Discovery of a Very High Energy Gamma-Ray Signal from the 3C 66A/B Region (2009) The Astrophysical Journal Letters, Volume 692, Issue 1, pp. L29-L33 (2009). (ADS)

doi: 10.1088/0004-637X/692/1/L29

302. Albert, J., Aliu, E., Anderhub, H., Antonelli, L.A., Antoranz, P., Backes, M., Baixeras, C., Barrio, J.A., Bartko, H., Bastieri, D., Becker, J.K., Bednarek, W., Berger, K., Bernardini, E., Bigongiari, C., Biland, A., Bock, R.K., Bonnoli, G., Bordas, P., Bosch-Ramon, V., Bretz, T., Britvitch, I., Camara, M., Carmona, E., Chilingarian, A., Commichau, S., Contreras, J.L., Cortina, J., Costado, M.T., Covino, S., Curtef, V., Dazzi, F., DeAngelis, A., DeCea del Pozo, E., de los Reyes, R., DeLotto, B., DeMaria, M., DeSabata, F., Delgado Mendez, C., Dominguez, A., Dorner, D., Doro, M., Errando, M., Fagiolini, M., Ferenc, D., Ferna'ndez, E., Firpo, R., Fonseca, M.V., Font, L., Galante, N., Garci'a Lo'pez, R.J., Garczarczyk, M., Gaug, M., Goebel, F., Hayashida, M., Herrero, A., Ho"hne, D., Hose, J., Hsu, C.C., Huber, S., Jogler, T., Kranich, D., La Barbera, A., Laille, A., Leonardo, E., Lindfors, E., Lombardi, S., Longo, F., Lo'pez, M., Lorenz, E., Majumdar, P., Maneva, G., Mankuzhiyil, N., Mannheim, K., Maraschi, L., Mariotti, M., Marti'nez, M., Mazin, D., Meucci, M., Meyer, M., Miranda, J.M., Mirzoyan, R., Mizobuchi, S., Moles, M., Moralejo, A., Nieto, D., Nilsson, K., Ninkovic, J., Otte, N., Oya, I., Panniello, M., Paoletti, R., Paredes, J.M., Pasanen, M., Pascoli, D., Pauss, F., Pegna, R.G., Perez-Torres, M.A., Persic, M., Peruzzo, L., Piccioli, A., Prada, F., Prandini, E., Puchades, N., Raymers, A., Rhode, W., Ribo', M., Rico, J., Rissi, M., Robert, A., Ru"gamer, S., Saggion, A., Saito, T.Y., Salvati, M., Sanchez-Conde, M., Sartori, P., Satalecka, K., Scalzotto, V., Scapin, V., Schmitt, R., Schweizer, T., Shayduk, M., Shinozaki, K., Shore, S.N., Sidro, N., Sierpowska-Bartosik, A., Sillanpaa”, A., Sobczynska, D., Spanier, F., Stamerra, A., Stark, L.S., Takalo, L., Tavecchio, F., Temnikov, P., Tescaro, D., Teshima, M., Tluczykont, M., Torres, D.F., Turini, N., Vankov, H., Venturini, A., Vitale, V., Wagner, R.M., Wittek, W., Zabalza, V., Zandanel, F., Zanin, R., Zapatero, J. Periodic Very High Energy ?-Ray Emission from LS I $+61^{\circ} 303$ Observed with the MAGIC Telescope (2009) The Astrophysical Journal, Volume 693, Issue 1, pp. 303-310 (2009). (ADS)

doi: 10.1088/0004-637X/693/1/303

303. Albert, J., Aliu, E., Anderhub, H., Antoranz, P., Baixeras, C., Barrio, J.A., Bartko, H., Bastieri, D., Becker, J.K., Bednarek, W., Berdyugin, A., Berger, K., Bigongiari, C., Biland, A., Bock, R.K., Bordas, P., Bosch-Ramon, V., Bretz, T., Brit- 
vitch, I., Camara, M., Carmona, E., Chilingarian, A., Commichau, S., Contreras, J.L., Cortina, J., Costado, M.T., Curtef, V., Danielyan, V., Dazzi, F., De Angelis, A., Delgado, C., De Los Reyes, R., De Lotto, B., Dorner, D., Doro, M., Errando, M., Fagiolini, M., Ferenc, D., Ferna'ndez, E., Firpo, R., Fonseca, M.V., Font, L., Fuchs, M., Galante, N., Garci'a-Lo'pez, R.J., Garczarczyk, M., Gaug, M., Goebel, F., Hakobyan, D., Hayashida, M., Hengstebeck, T., Herrero, A., Ho”hne, D., Hose, J., Hsu, C.C., Huber, S., Jacon, P., Jogler, T., Kosyra, R., Kranich, D., Kritzer, R., Laille, A., Lindfors, E., Lombardi, S., Longo, F., Lo’pez, M., Lorenz, E., Majumdar, P., Maneva, G., Mannheim, K., Mariotti, M., Marti’nez, M., Mazin, D., Merck, C., Meucci, M., Meyer, M., Miranda, J.M., Mirzoyan, R., Mizobuchi, S., Moralejo, A., Nieto, D., Nilsson, K., Ninkovic, J., Ona-Wilhelmi, E., Otte, N., Oya, T., Panniello, M., Paoletti, R., Pasanen, M., Pascoli, D., Pauss, F., Pegna, R., Persic, M., Peruzzo, L., Piccioli, A., Prandini, E., Puchades, N., Raymers, A., Rico, J., Rhode, W., Rissi, M., Robert, A., Ru"gamer, S., Saggion, A., Saito, T.Y., Sanchez, A., Sartori, P., Scalzotto, V., Scapin, V., Schmitt, R., Schweizer, T., Shayduk, M., Shinozaki, K., Shore, S.N., Sidro, N., Sillanpaa”, A., Sobczynska, D., Spanier, F., Stamerra, A., Stark, L.S., Takalo, L., Temnikov, P., Tescaro, D., Teshima, M., Torres, D.F., Turini, N., Vankov, H., Venturini, A., Vitale, V., Wagner, R.M., Wibig, T., Wittek, W., Zandanel, F., Zanin, R., Zapatero, J. MAGIC observations of PG 1553+113 during a multiwavelength campaign in July 2006 (2009) Astronomy and Astrophysics, 493 (2), pp. 467-469. Cited 9 times. Article

\section{Continuation of the Basic Space Science Initiative beyond 2012}

The Basic Space Science Initiative will continue providing support to operators of planetariums, astronomical telescopes, and ISWI instruments.

\section{Astronomical telescopes}

The International Scientific Optical Network (ISON) is an open international non-government project mainly aimed at being a free source of information on space objects for scientific analysis and other applications. It was initiated in the framework of the programme of the GEO region investigations started by the Keldysh Institute of Applied Mathematics (KIAM) of the Russian Academy of Sciences in 2001 and in order to support space debris radar experiments with additional tracking data used for determination of orbital parameters precise enough to properly point narrow radar beams of selected objects.

ISON is one of the largest observation systems and it is one of two existing systems in the world, capable to observe the sky globally from both-Eastern and Western-hemispheres. At present, there are more than 30 telescopes operating in 20 observatories in eight nations: Bolivia, Georgia, Italy, Moldova, Russia, Tajikistan, Ukraine, Uzbekistan. All these telescopes participate in a coordinated observation programme under the ISON project.

ISON telescopes are grouped in three subsets dedicated to tracking of different classes of the space objects-bright GEO-objects, faint fragments at GEO region, 
bright objects at highly elliptical (HEO), and low orbits (LEO). ISON activities are arranged with four supporting groups such as 1) electric and software engineering, 2) optical and mount engineering, 3) observation planning and data processing, and 4) network development. The obtained data are collected and stored at the KIAM Centre for Processing and Analysis of Information on Space Debris (CCPAISD), Russian Academy of Sciences.

The goal of the ISON observations of faint space debris fragments at high orbits was formulated from the beginning of the establishment of ISON in 2004. First experiments arranged with a $64 \mathrm{~cm}$ telescope AT-64 in Nauchny, Crimea, in October 2004 were devoted to adjusting of a method of the fragments discovering and checking of the Pulkovo theory on orbital evolution of the GEO object explosion fragments. These successful attempts, discovering seven not catalogued fragments and obtaining 1240 measurements in 18 tracks, initiated also the cooperation with a team at the Astronomical Institute of the University of Bern (AIUB), Switzerland. The regularly coordinated AIUB-ISON observing campaigns were carried out during 2005 and the ISON subsystem for the tracking of the faint fragments at GEO region started operations in 2006. ISON news are regularly published in a dedicated website: http://www.lfvn.astronomer.ru.

\section{Planetariums}

The recently published book titled Max Goes to the Moon has been donated by author Jeffrey Bennett (http://www.jeffreybennett.com) and provided to public educational institutions by the Office for Outer Space Affairs of the United Nations (http://www.unoosa.org). Max Goes to the Moon was the first children's book selected to be read aloud in space, by Astronaut Alvin Drew aboard the final mission of the Space Shuttle Discovery. To see a video of the reading, go to http://www.bigkidscience.com/max_in_space. Planetariums in your region can obtain materials for a Max Goes to the Moon planetarium show at no cost. A variety of other free educational resources related to this and other books in the Max series are available at http://www.BigKidScience.com. Jeffrey Bennett also distributes e-mails with educational information about space science. Educational institutions that are using the book are invited to provide brief information on ways and means to incorporate the book into their educational activities to the Office for Outer Space Affairs of the United Nations.

\section{Space weather instruments}

In 2012, the Scientific and Technical Subcommittee of COPUOS, at its forty-ninth session, agreed that an agenda item entitled "Space Weather" should be introduced as a regular item on the agenda of the Subcommittee, in order to allow member States of COPUOS and international organizations having permanent observer status with COPUOS to exchange views on national, regional, and international activities related to space weather research with a view to promoting greater international cooperation in that area. The Subcommittee noted that it could, through that item, serve as an important advocate for efforts to close existing gaps in the space weather research field (A/AC.105/1001, para. 226). 
Space weather is important to society, which increasingly relies on technology for education, business, transportation and communication. Space storms can disrupt GPS/GNSS reception and long distance radio transmission. Modern oil and gas drilling frequently involve directional drilling to tap oil and gas reservoirs deep in the Earth, thus depending on accurate positioning using GPS systems. Energetic particles at the magnetic poles can force re-routing of polar airline flights resulting in delays and increased fuel consumption. Ground induced currents generated by magnetic storms can cause extended power blackouts and increased corrosion in critical energy pipelines.
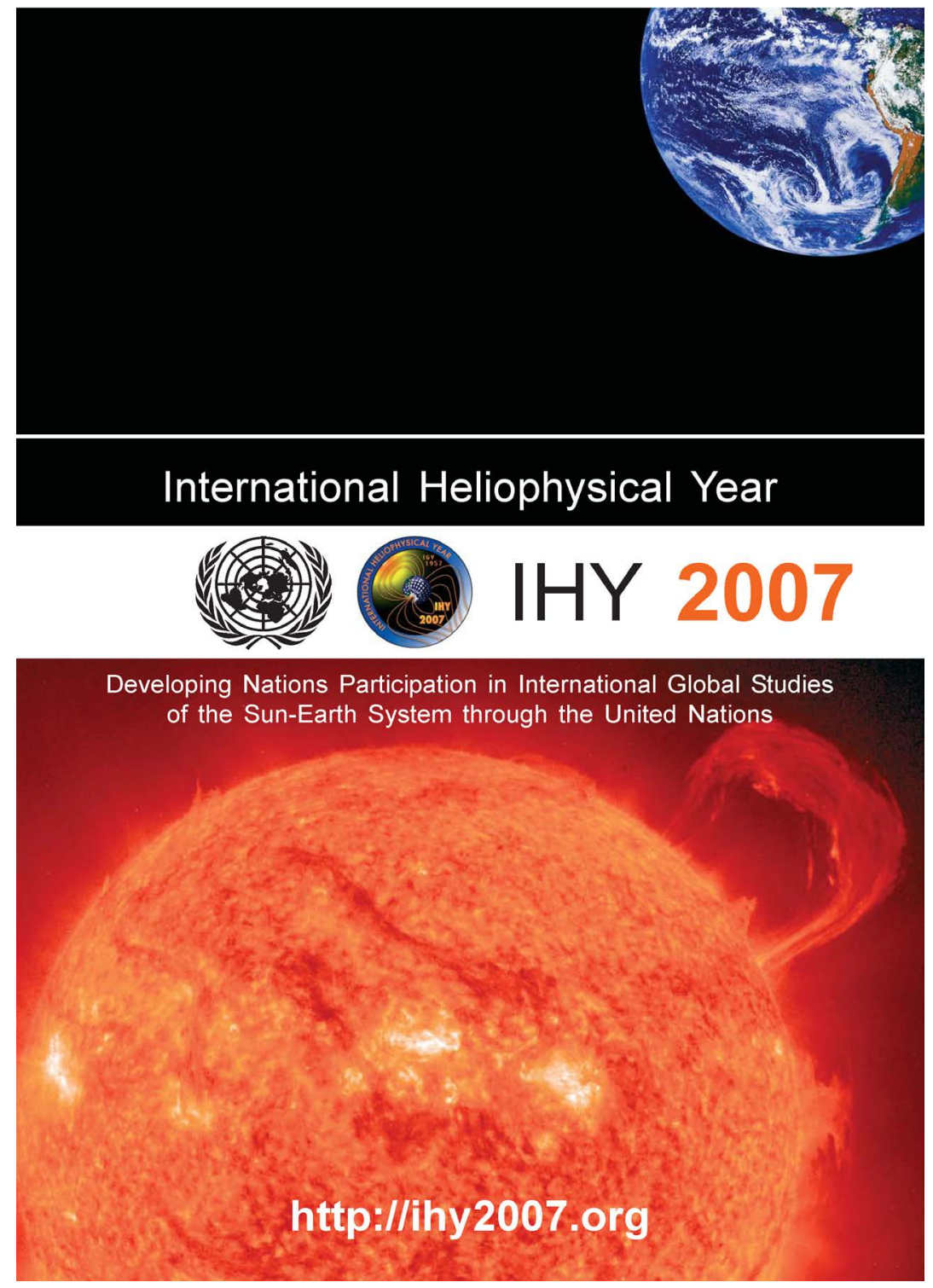

Cover page of UN developed information material for IHY 2007 that was made available on the WWW and in print in all six official languages of the United Nations: http://www.unoosa.org/oosa/en/ourwork/psa/bssi/ihy2007.html.

In addition, space weather likely affects Earth's climate. The amount of energy 
entering the troposphere and stratosphere from all space weather phenomena is trivial compared to the solar insolation in the visible and infrared portions of the solar electromagnetic spectrum. However, there does seem to be some linkage between the 11-year sunspot cycle and Earth's climate. For example, the Maunder minimum, a 70 year period almost devoid of sunspots, correlates with a cooling of Earth's climate.

Space weather is inherently an international enterprise. Solar and magnetic storms can affect large regions of the Earth simultaneously, and equatorial ionospheric disturbances occur routinely around the globe. It is therefore appropriate for the United Nations to promote improvement in space weather modelling and forecasting for the benefit of all nations.

There has been significant scientific progress over the past decade in developing physics-based space weather models, and large-scale coupled (real-time) space plasma simulations. However, these models are limited by still being data starved in various spatial space weather domains. Thus, there is a crucial need for guaranteed continuous space weather data streams.

In 2007, the International Heliophysical Year (IHY) and International Space Weather Initiative (ISWI) have made significant progress in the installation of new instrumentation for the understanding of space weather impacts on Earth's upper atmosphere, generating new data streams useful for space weather in regions unobserved before. With the support of the United Nations Office of Outer Space Affairs (OOSA), the ISWI has facilitated the operation of nearly 1000 instruments operating in 100 of the UN's 194 Member States. The data from these instrument arrays is a unique resource for the study of space weather influences on Earth's atmosphere. The IHY and ISWI schools have trained several hundred graduate students and young scientists, many of whom are maturing as fine scientists as evidenced by their publications.

\section{ISWI Scientific Objectives and Programme}

At the 2011 UN/Nigeria Workshop on ISWI (A/AC.105/1018), the desire for a programme to enhance the science from ISWI was announced. The announcement also appeared at that time in the ISWI Newsletter (http://iswi-secretariat.org/). This was followed up by a presentation and subsequent discussion of an ISWI science plan at the 2012 UN/Ecuador Workshop on ISWI (A/AC.105/1030), resulting in the following observations and recommendations.

The overall ISWI objective is to develop the scientific insight necessary to understand the science, and reconstruct and forecast near-Earth space weather. Steps in this process include: 1) Expanding and continuing the deployment of the existing ISWI instrument arrays and add new arrays as appropriate. 2) For the data being obtained by the arrays, expanding the data analysis effort for array data and using existing data bases. 3) Coordinating the data products to provide inputs for physical modelling, input instrument array data into physical models of heliospheric processes, and developing data products that reconstruct past conditions in order to facilitate assessment of problems attributed to space 
weather effects. 4) Coordinating the data products to permit predictive relationships to be developed, to develop data products yielding predictive relationships that enable the forecasting of Space Weather, and to develop data products that can easily be assimilated into real-time or near real-time predictive models.

Fundamental aspects of ISWI include education and training, and public outreach activities. The concept is to encourage and support space science courses, workshops and curricula in university and graduate schools that provide instrument support. There has been much success in these areas, but there is a strong need to continue the education and training, develop public outreach materials that are unique to ISWI, and coordinate their distribution. It is important to provide information on ISWI instruments and results to the media, especially to local media.

The overall goal of an ISWI science programme should be to gain a more complete understanding of the universal processes that govern the Sun, Earth, planets, and heliosphere. This must involve scientists from a variety of disciplines, such as Solar Physics, Planetary Magnetospheres, Heliosphere and Cosmic Rays, Planetary Ionospheres, Thermospheres and Mesospheres, and Climate Studies. ISWI science projects should focus on the fundamental underlying physics of each phenomenon. They should facilitate discussions between different disciplines by focusing on relationships between these phenomena and commonalities in the physical processes. This allows researchers to plan and participate in cross-disciplinary studies, culminating in a greater understanding of fundamental universal processes.

What are the science benefits? This question is informed by recognizing what is unique about the ISWI data sets: 1) By observing in new geographical regions, a more global picture of Earth's response to solar wind inputs can be obtained;

2) $24 / 7$ solar observing is obtained in the radio and $\mathrm{H}$-alpha wavelength regimes; 3) Arrays provide global, 3-D information that can be used in tomographic reconstructions; 4) Over the long term, these arrays will provide real-time data valuable for forecasting and now casting; and 5) Modelling improvements will allow better exploitation of existing data sets.

Enhancing the Science from ISWI

The primary data sets for ISWI science should come from the ISWI (IHY Legacy) Instrument Projects/Arrays. There are currently 16 operational instrument arrays hosted by $\sim 100$ nations. Current scientific activities sponsored by ISWI will continue. Specific recommendations are:

1) The ISWI will continue the deployment of instruments both for existing instrument arrays and for new instrument arrays on a perpetual basis.

2) The ISWI will undertake a process to use ISWI instrument data sets to determine data utility, to develop connections with virtual observatories to make data more readily available, and to facilitate collaborative modelling of regions of interest (e.g., the equatorial ionosphere) in collaboration with modelling centres of the ESA JAXA, NASA and others. 
3) Data from ISWI instrument arrays will be combined with space-based data to advance space weather science leading to quality papers in international journals.

4) Space Science Schools are an integral part of ISWI, providing training for young and new researchers in instrument operation and the science of heliophysics. ISWI Space Science Schools will continue, and partnerships with organizations such as SCOSTEP and the International Astronomical Union will be established or strengthened to assure that these capacity building activities are accomplished efficiently and for the benefit of all member States.

Another new aspect of ISWI might include coordinated programmes or campaigns modelled on the Coordinated Investigation Programmes (CIPs) established under the International Heliophysical Year (IHY). These could use the same principles as the IHY scientific activities, but need not be as formal as the CIPs were. General CIP science topics included cosmic rays, solar filaments, CME onset and propagation, incoherent scatter radar data and comparative aeronomy.

The main communication interface for ISWI science should be an internet site set up either directly through or via a link to the main ISWI website at http://www.iswi-secretariat.org/. The science program can aid in establishing space weather modelling centres around the world, e.g., in collaboration with NASA's Coordinated Community Modeling Center (CCMC) at http://ccmc.gsfc.nasa.gov/. It would provide an interface for ISWI science results with the ISWI Space Science Schools and Public Outreach projects. Specific details on developments of the ISWI science programme will be made available through the ISWI Newsletter.

One way of developing and promoting scientific results from ISWI could be to have one or more ISWI science workshops, the first possibly as early as next year, 2013. The workshop would focus on scientific results. This or a follow on workshop could be like a NASA Coordinated Data Analysis Workshop (CDAW) in which the data interfaces and analysis tools are prepared in advance, and the results are presented at one or more later meetings and then published together in one volume.

Developing Data Analysis Links between ISWI Projects andlor with Outside Projects

In the following, some recent examples of cooperative science projects already underway or planned that involve ISWI array data. These include some examples of combining data from several ISWI arrays and with other "outside" data sources.

The Continuous $\mathrm{H}$-alpha Imaging Network (CHAIN) project, with PIs K. Shibata and S. Ueno of Japan, has the goal of forming an worldwide $\mathrm{H}$-alpha observing network for understanding and predicting space weather by accurately observing erupting phenomena on the solar surface that are initial boundary conditions of all eruptive processes. Its scientific goals are determination of the 3-D velocity field of eruptive phenomena on the solar surface, detection of shock 
waves (Moreton waves) generated by solar explosive phenomena, and estimation of solar UV radiation and comparison with ionospheric variation. The CHAIN group is seeking partnerships for using these data in international cooperative studies. For example, this year they plan to work with the Pakistan Space and Upper Atmosphere Research Commission (SUPARCO) to study F2 ionospheric density variations during solar minimum and maximum conditions, ionospheric variability at low and mid latitudes for solar cycles 22 and 23 , and solar cycle effects on coupling of neutral and ionized species at F2 altitude.

The Compact Astronomical Low-cost Low-frequency Instrument for Spectroscopy in Transportable Observatories (CALLISTO), PIs A. Benz and C. Monstein (ETHZ, Switzerland), is a radio spectrometer using a heterodyne receiver build by the ETH Zürich Radio and Plasma Physics Group. CALLISTO is able to continuously cover the solar radio spectrum from 45 to $870 \mathrm{MHz}$, using modern, commercially available broadband cable-TV tuners having frequency resolution of $62.5 \mathrm{KHz}$. CALLISTO has now deployed 56 instruments in more than 30 locations with users from more than 74 countries. It produces science quality data and detects even tiny eruptions from the Sun. The spectral data on solar radio bursts is being used by the solar community but needs wider distribution. CALLISTO data is now being utilized for an Indo-US project on solar eruptive events. With this large network CALLISTO provides 24/7 coverage of radio bursts. Future plans include identifying sets of similar instruments to provide more continuous coverage over the whole frequency range.

The African Meridian B-Field Education and Research (AMBER), PI's E. Yizengaw (Boston College, USA) and M. Moldwin (University of Michigan, USA), is a magnetometer array comprised of four magnetometers stationed in Ethiopia, Algeria, Cameroon, and in Namibia. AMBER's data are being combined with other related arrays to provide important new observations for these objectives: 1) To monitor the electrodynamics governing the motion of plasma in the low/mid-latitude as function of LT, season, and magnetic activity; 2) To understand ULF pulsation strength into low/mid-latitudes and its connection with EEJ and EA; 3) To support studies about the effects of Pc5 ULF waves on the MeV electron population in the inner parts of the Van Allen belts. Recently, in collaboration with the SAMBA (E. Zesta, AFRL, USA) project, a fifth magnetometer was deployed in Nigeria. Other non-ISWI networks that are being used with AMBER are LISN (C. Valladares, Boston College, USA) in South America and MEASURE (M. Moldwin) in North America. AMBER is working to coordinate with other ground-based magnetometer arrays to provide a worldwide network to understand the electrodynamics that governs equatorial ionosphere motions. Data from the AMBER and related magnetometer arrays will be made accessible to space weather forecasters and the space science community at large.

There are several international programmes for which the use of ISWI data is planned. The International Study of Earth-Effecting Solar Transients (ISEST) is coordinated by Jie Zhang of George Mason University, USA, and is being imple- 
mented in 2012-2013 under the framework of Task Group 3 of SCOSTEP/ CAWSES II. Its goals are: 1) To organize three international workshops; 2) To promote an international effort to create a comprehensive database of Earth-effecting solar and heliospheric transient events in solar cycle 23 and 24, to develop advanced theoretical models of heliospheric transients, and to develop prediction tools for heliospheric transients. Another program is an ISWI Study of Radio Transients coordinated by N. Gopalswamy of the ISWI Secretariat. Two other international programmes that D. Webb coordinates are the IAU Working Group on International Collaboration on Space Weather and the STEREO mission Space Weather Group. Both of these could utilize ISWI data.

Listing 2 lists published scientific papers that used ISWI array data using the Astrophysics Data System (ADS).

\section{Conclusion}

Space weather research is beneficial to the technological society. The ISWI makes an important and unique contribution by developing new data sources necessary for improved space weather understanding and prediction. The initial emphasis in ISWI has been on studies with analyses of data from individual ISWI instrument arrays. It is now time to expand these studies and it is recommended that, where possible and scientifically justified, these projects include cooperative studies with data sets from other ISWI arrays and other "outside" data sets to best address and expand the science results. Above a few examples of such expanded projects utilizing data from the ISWI arrays are given. It is recommended that these projects continue to interface with the ISWI Space Science Schools, Public Outreach projects and other educational science programmes. The ISWI community at large also would like to receive feedback from the PI groups of the instrument arrays and projects on how best to proceed on enhancing ISWI science. It is expected that any new data plan or procedures will be part of the proposed new permanent agenda item "Space Weather" for the Scientific and Technical Subcommittee of COPUOS.

\section{Acknowledgements}

The authors are grateful to all who have joined the long process of implementation of the UNBSSI since 1988, especially those who took part in the workshops. Special thanks to ESA, NASA, and JAXA for all support provided. Committees established for IHY 2007 and ISWI have been very instrumental to the success of the initiative. Host countries of the workshops and their respective Governments and expert groups provided enlightening support and guidance for the cultural and scientific atmosphere to the whole initiative.

\section{Disclaimer}

The views expressed in this paper are solely those of the authors and do not necessarily reflect the views of any company or organization. 


\section{References}

Smith, D. W., \& Haubold, H. J. (Eds.) (1992). Planetarium: A Challenge for Educators, United Nations, New York. http://www.unoosa.org/pdf/publications/planetariumE.pdf

Thompson, B. J., Gopalswamy, N., Davila, J. M., \& Haubold, H. J. (Eds.) (2009). Putting the "I" in IHY: The United Nations Report for the International Heliophysical Year 2007. Wien-New York: Springer.

Wamsteker, W., Albrecht, R, \& Haubold, H. J. (Eds.) (2004). Developing Basic Space Science World-Wide: A Decade of UN/ESA Workshops. Dordrecht-Boston-London: Kluwer Academic Publishers.

\section{Appendix}

The Working Group on Space Sciences in Africa (http://www.saao.ac.za/ wgssa/) is an international, non-governmental organisation founded by African delegates at the 6th United Nations/European Space Agency Workshop held in Bonn on 9-13 September 1996. The scientific scope of the Working Group's activities is defined to encompass: astronomy and astrophysics, solar-terrestrial interaction and its influence on terrestrial climate, planetary and atmospheric studies, and the origin of life and exobiology. The Working Group seeks to promote the development of the space sciences in Africa by initiating and coordinating various capacity-building programmes throughout the region. These programmes fall into a broad spectrum ranging from the promotion of basic scientific literacy in the space sciences to the support of international research projects. The Working Group also promotes international cooperation among African space scientists and acts as a forum for the exchange of ideas and information through its publications, outreach programmes, workshops, and scientific meetings. Since the above workshop, WGSSA is publishing an annual volume on new developments in astronomy in Africa, including achievements of the basic space science initiative (http://www.saao.ac.za/ wgssa/archive.php). 